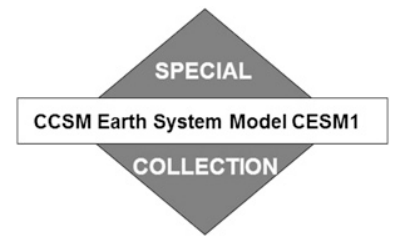

\title{
Marine Ecosystem Dynamics and Biogeochemical Cycling in the Community Earth System Model [CESM1(BGC)]: Comparison of the 1990s with the 2090s under the RCP4.5 and RCP8.5 Scenarios
}

\author{
J. KEITH MOORE \\ Earth System Science, University of California, Irvine, Irvine, California \\ KEITH LINDSAY \\ Climate and Global Dynamics Division, National Center for Atmospheric Research, Boulder, Colorado \\ SCOTT C. DONEY \\ Marine Chemistry and Geochemistry, Woods Hole Oceanographic Institution, Woods Hole, Massachusetts \\ MATTHEW C. LONG \\ Climate and Global Dynamics Division, National Center for Atmospheric Research, Boulder, Colorado \\ KAZUHIRO MISUMI \\ Environmental Science Research Laboratory, Central Research Institute of Electric Power Industry, Abiko, Chiba, Japan
}

(Manuscript received 3 August 2012, in final form 28 May 2013)

\begin{abstract}
The authors compare Community Earth System Model results to marine observations for the 1990s and examine climate change impacts on biogeochemistry at the end of the twenty-first century under two future scenarios (Representative Concentration Pathways RCP4.5 and RCP8.5). Late-twentieth-century seasonally varying mixed layer depths are generally within $10 \mathrm{~m}$ of observations, with a Southern Ocean shallow bias. Surface nutrient and chlorophyll concentrations exhibit positive biases at low latitudes and negative biases at high latitudes. The volume of the oxygen minimum zones is overestimated.

The impacts of climate change on biogeochemistry have similar spatial patterns under RCP4.5 and RCP8.5, but perturbation magnitudes are larger under RCP8.5. Increasing stratification leads to weaker nutrient entrainment and decreased primary and export production ( $>30 \%$ over large areas). The global-scale decreases in primary and export production scale linearly with the increases in mean sea surface temperature. There are production increases in the high nitrate, low chlorophyll (HNLC) regions, driven by lateral iron inputs from adjacent areas. The increased HNLC export partially compensates for the reductions in nonHNLC waters ( $\sim 25 \%$ offset). Stabilizing greenhouse gas emissions and climate by the end of this century (as in RCP4.5) will minimize the changes to nutrient cycling and primary production in the oceans. In contrast, continued increasing emission of $\mathrm{CO}_{2}$ (as in RCP8.5) will lead to reduced productivity and significant modifications to ocean circulation and biogeochemistry by the end of this century, with more drastic changes beyond the year 2100 as the climate continues to rapidly warm.
\end{abstract}

Corresponding author address: J. Keith Moore, Earth System Science, University of California, Irvine, Croul Hall, Irvine, CA 92697-3100.

E-mail: jkmoore@uci.edu

\section{Introduction}

The Biogeochemical Elemental Cycling (BEC) model is a module of the Community Earth System Model (CESM) that simulates ocean biogeochemistry and 
lower-trophic-level marine ecosystem dynamics. The BEC model includes multiple phytoplankton functional groups and tracks the cycling of key elements in the oceans $(\mathrm{C}, \mathrm{N}, \mathrm{P}, \mathrm{Fe}, \mathrm{Si}$, and $\mathrm{O})$. The purpose of this paper is to document the performance of the BEC module within the coupled CESM for the period of the 1990s and to examine the predicted changes to ecosystem structure and biogeochemistry under two warming scenarios for the twenty-first century [Representative Concentration Pathways (RCPs) RCP4.5 and RCP8.5]. The CESM is one of a number of models participating in phase 5 of the Coupled Model Intercomparison Project (CMIP5) that will inform the next (fifth) assessment report of the Intergovernmental Panel on Climate Change (IPCC).

The BEC model is one of a number of "dynamic green ocean" models (DGOMs; Le Quéré et al. 2005; see also Boyd and Doney 2002; Hood et al. 2006; Doney et al. 2012) developed over the past decade for use in conjunction with traditional physical climate models to look at climate-biogeochemistry interactions and improve climate change predictions in the context of a changing Earth system. The international Joint Global Ocean Flux Study (JGOFS) played a key role in the development of these models, through intensive field campaigns in key ocean regions and a significant synthesis and modeling effort (e.g., Doney and Ducklow 2006). DGOMs include representations of the key plankton functional groups mediating the cycling of carbon and associated elements in the oceans. Thus, environmental variables driven by climate change and other anthropogenic perturbations can impact plankton community composition, marine biogeochemistry, and feedback onto climate change, primarily by modifying air-sea $\mathrm{CO}_{2}$ exchange.

The BEC model has been used extensively in the context of the Community Climate System Model (CCSM, the forerunner of CESM). There were few changes made to the BEC model for this initial implementation in the CESM, version 1.0 (CESM1). Thus, the model skill assessment gives similar results to previous work (e.g., Moore et al. 2004; Friedrichs et al. 2007; Doney et al. 2009a). CESM1 includes three explicit phytoplankton functional groups (diatoms, diazotrophs, and smaller phytoplankton), and one implicit group (calcifiers) described originally by Moore et al. (2002b, 2004).

The BEC model was one of the first to estimate the spatial patterns of nutrient limitation of growth for different phytoplankton groups (Moore et al. 2002a, 2004). The model has been used extensively to study the impacts of atmospheric nutrient deposition on marine productivity and biogeochemistry (Moore et al. 2006; Krishnamurthy et al. 2007, 2009, 2010; Patra et al. 2007; Doney et al. 2007; Han et al. 2008). The marine nitrogen cycle has been another focus, with papers examining internal feedbacks within the marine $\mathrm{N}$ cycle (Moore and Doney 2007) and papers addressing interactions between the marine iron and nitrogen cycles (Moore et al. 2006; Krishnamurthy et al. 2009). The model has also provided insight into the factors governing dissolved inorganic carbon (DIC) distributions and air-sea exchange of $\mathrm{CO}_{2}$ (Lovenduski et al. 2008; Doney et al. 2009a; Wang and Moore 2011; Wang et al. 2012). Finally, the model has been used in coupled carbon-climate simulations in the CCSM3.1 model to examine the biogeochemical feedbacks on climate change and to predict the ocean response to climate change over the twentyfirst century (Thornton et al. 2009; Marinov et al. 2010; Steinacher et al. 2010; Mahowald et al. 2011).

A number of previous studies have attempted to predict the response of marine ecosystems to climate change at the global scale. One consistent result is a reduction in total export production [sinking flux of particulate organic carbon (POC)] due to increasing stratification, driven by upper-ocean warming and surface freshening in some higher-latitude regions (e.g., Maier-Reimer et al. 1996; Matear and Hirst 1999; Joos et al. 1999; Bopp et al. 2001; Schmittner et al. 2008; Frölicher et al. 2009; Steinacher et al. 2010). Many, but not all, of these studies also found reductions in primary production. Steinacher et al. (2010) compared the results from four coupled carbon-climate simulations [including two earlier versions of the CESM, Climate System Model 1.4 (CSM1.4) and CCSM3.1] to examine the impacts of climate change over the twenty-first century [Special Report on Emissions Scenarios (SRES) A2 emission scenario] on primary and export production. All four models had decreased lower-latitude export by the end of the century because of increasing stratification. CCSM3.1 had the smallest global reduction in export production $(2 \%)$ as increased export in some high-latitude regions partially compensated for the lower-latitude reductions. At higher latitudes, production in some models increased because of reductions in light limitation (decreased sea ice cover, shallower mixed layer depths) and/or increased growth rates due to rising temperatures. Taucher and Oschlies (2011) argued that correctly incorporating the metabolic sensitivity of planktonic organisms to rising temperatures is critical for predicting how primary production will respond to twenty-first-century climate change.

This paper complements several papers from the CCSM4 and CESM special issues. Gent et al. (2011) gives an overview of the CCSM4 climate model. The physical ocean component is documented by Danabasoglu et al. (2011), and the Southern Ocean model behavior is examined in detail in Weijer et al. (2012). Lindsay et al. 
(2012, manuscript submitted to J. Climate) describe the overall model setup, spinup under preindustrial-era conditions, and key twentieth-century transient simulations (including the prognostic atmospheric $\mathrm{CO}_{2}$ simulation examined here). Long et al. (2013) examine twentieth-century uptake and storage of anthropogenic $\mathrm{CO}_{2}$, and document the end of twentieth-century simulated surface $p \mathrm{CO}_{2}$, DIC, and alkalinity fields for the CESM1-Biogeochemistry (BGC). Simulated atmospheric $\mathrm{CO}_{2}$ concentrations and variability are examined by Keppel-Aleks et al. (2013). Arctic sea ice simulations for the late twentieth century have been described in detail by Jahn et al. (2012) and for the twenty-first century by Vavrus et al. (2012). In addition, Long et al. (2013, manuscript submitted to J. Climate) examine the time series of marine carbon fluxes over the twenty-first century.

\section{Methods}

CESM1 builds on its predecessor, CCSM4, with enhanced Earth system capabilities, including incorporation of biogeochemical cycles, atmospheric chemistry, and simple ice sheet dynamics (Hurrell et al. 2013). The CESM1 marks the first public release of the marine ecosystem and ocean biogeochemistry module, the BEC model. The structure of the model and aspects of its behavior have been documented in a number of earlier papers. There were few modifications other than minor parameter value changes for the initial CESM implementation, with the iron cycle modifications by Moore and Braucher (2008) being the last major modification to the BEC model code. Here we provide a brief overview of the model components and capabilities with references to the earlier papers for additional details. The version of the CESM described here, CESM1(BGC), uses active biogeochemistry (Lindsay et al. 2012, manuscript submitted to J. Climate). A key focus of this paper is comparing biogeochemical tracers from a twentiethcentury simulation, averaged over the 1990s, with observational datasets. This simulation is the twentiethcentury, prognostic atmospheric $\mathrm{CO}_{2}$ (20C PROG) experiment described by Lindsay et al. (2012, manuscript submitted to J. Climate). The physics of the CESM1 (BGC) are identical to the CCSM4 model, except that in CESM1(BGC) shortwave radiation absorption is computed using the simulated chlorophyll field, rather than the satellite-based chlorophyll climatology used in CCSM4. This difference has little effect (see Lindsay et al. 2012, manuscript submitted to J. Climate), since the simulated chlorophyll distributions are in reasonable agreement with observations. Thus, we make reference to recently published CCSM4 papers concerning the physical state of the model. Additional documentation, model output, and all model source code are available online (www2.cesm.ucar.edu).

The BEC module runs within the ocean physics component of CESM1 (Gent et al. 2011), which is the Parallel Ocean Program, version 2 (Smith et al. 2010). A detailed description and evaluation of the ocean general circulation model is given by Danabasoglu et al. (2011; see also Bates et al. 2012). It has a nominal horizontal resolution of $1^{\circ}$, with 60 vertical levels ranging in thickness from $10 \mathrm{~m}$ (in the upper $150 \mathrm{~m}$ ), with layer thickness increasing with depth below $150 \mathrm{~m}$. The CESM1 sea ice component is the Community Ice Code, version 4 (CICE4; Hunke and Lipscomb 2008). The continental ice sheet model is not active in the simulations presented here.

The BEC model includes key phytoplankton functional groups, zooplankton, semilabile dissolved organic matter (with variable $\mathrm{C} / \mathrm{N} / \mathrm{P} / \mathrm{Fe}$ ratios), sinking particulates $\left(\mathrm{C}, \mathrm{N}, \mathrm{P}, \mathrm{Fe}, \mathrm{CaCO}_{3}\right.$, biogenic $\mathrm{Si}$, and mineral dust particles), dissolved nitrate, ammonium, phosphate, iron, silicate, oxygen, inorganic carbon, and alkalinity (Moore et al. 2002b, 2004). The model has been validated against extensive global datasets (Moore et al. 2002a, 2004; Moore and Braucher 2008; Doney et al. 2009b, Long et al. 2013) and includes full carbonate system thermodynamics, allowing for dynamic computation of inorganic carbon chemistry, oceanic $p \mathrm{CO}_{2}$, and air-sea $\mathrm{CO}_{2}$ and $\mathrm{O}_{2}$ flux. The model includes several key phytoplankton functional groups (diatoms, diazotrophs, coccolithophores, and smaller phytoplankton). Coccolithophores are simulated as a dynamically variable fraction of the small phytoplankton group (Moore et al. 2004).

Key differences between the phytoplankton functional groups include efficient nutrient uptake by the small phytoplankton (with higher half-saturation constants for nutrient uptake by the diatoms and diazotrophs). The small phytoplankton experience moderately higher grazing pressure than the diatoms, with much lower grazing rates on the diazotrophs. This leads to diatom domination of blooms under nutrient-replete conditions. The export efficiency of the diatoms through losses to aggregation and grazing is higher than for the other phytoplankton groups. Phytoplankton growth rates and zooplankton grazing rates are scaled by a temperature function based on a Q10 value of 2.0 (Moore et al. 2004).

Phytoplankton growth and primary production are a function of available light, nutrients, and temperature in a multiplicative fashion (Moore et al. 2002b, 2004). Stoichiometric elemental C/N/P ratios are fixed within the phytoplankton, zooplankton, and sinking particulate organic matter (POM) pools at 117/16/1 (molar ratios). 
The exception is the diazotroph group, which has lower $\mathrm{P}$ requirements and a fixed N/P ratio of 50 (Moore et al. 2004). Iron quotas (Fe/C ratios) vary across groups (higher for diazotrophs) and adjust dynamically to ambient iron concentrations (Moore et al. 2004). The model uses a single adaptive zooplankton type with routing of grazed materials varying depending on prey type. For example, a higher fraction of grazed POM is routed to sinking export when diatoms are the prey group, compared with grazing on smaller phytoplankton (Moore et al. 2002b, 2004).

In previous BEC implementations, the diazotrophs obtained all the nitrogen necessary for growth from $\mathrm{N}$ fixation (Moore et al. 2002b, 2004). In the CESM implementation, the diazotrophs are able to take up nitrate and ammonium when available, reducing $\mathrm{N}$ fixation proportionately. Partitioning of the $\mathrm{N}$ uptake by diazotrophs is similar to the partitioning between ammonium and nitrate uptake for the other phytoplankton groups (Moore et al. 2002b). The half-saturation constants for uptake of nitrate and ammonium are set relatively high relative to the small phytoplankton and diatom groups (nitrate values are $0.1 \mu \mathrm{M}$ for diazotrophs, $0.05 \mu \mathrm{M}$ for diatoms, and $0.01 \mu \mathrm{M}$ for the small phytoplankton). Thus, diazotrophs are not strongly competing for these dissolved inorganic nitrogen (DIN) pools in the oligotrophic, low- $\mathrm{N}$ regions, where most of their $\mathrm{N}$ uptake still comes from fixation. However in some regions, like the equatorial Pacific, where nitrate and ammonium concentrations are high, a majority of diazotroph $\mathrm{N}$ uptake is not from $\mathrm{N}$ fixation. $\mathrm{N}$ fixation and diazotroph biomass are generally low in these Fe-limited, N-rich regions. We do not account for any reduction in energy costs associated with DIN uptake, rather than $\mathrm{N}$ fixation.

Holl and Montoya (2005) showed that one key diazotroph, Trichodesmium, progressively reduces $\mathrm{N}$ fixation and increases uptake of inorganic nitrogen as ambient nitrate concentrations increase in culture. Other studies have demonstrated diazotroph uptake of ammonium (Mulholland and Capone 1999, 2001; Mulholland et al. 1999, 2004). Thus, incorporating this capability makes the simulations of the diazotrophs more realistic and may improve the spatial patterns of where $\mathrm{N}$ fixation occurs in the oceans.

The model includes water column denitrification, with a transition from oxic degradation to denitrification across $\mathrm{O}_{2}$ concentrations from 6 to $4 \mu \mathrm{M}$ (Moore and Doney 2007). Initial CESM experiments revealed a large overestimation of the volume of low- $\mathrm{O}_{2}$ waters (see section 3) and water column denitrification, such that the preindustrial $\mathrm{N}$ cycle was very unbalanced (see also Moore and Doney 2007). The extent of this problem was such that the preindustrial $\mathrm{N}$ cycle could not come into balance without an unacceptably large (and unrealistic) loss of fixed $\mathrm{N}$ from the oceans. Thus, for the CESM1 BEC implementation, we applied a scaling factor to force reductions in water column denitrification (Lindsay et al. 2012, manuscript submitted to J. Climate). We multiply the fixed $\mathrm{N}$ removal rate [based on ambient oxygen concentration and the remineralization of organic matter, as in Moore and Doney (2007)] times the simulated nitrate concentration divided by a factor of 110 . This coefficient value of 110 was chosen to push the simulated denitrification toward more realistic rates (from initial rates exceeding $400 \mathrm{TgN} \mathrm{yr}^{-1}$ ). Recent observation and inverse model estimates of water column denitrification range from 45 to $90 \mathrm{TgN} \mathrm{yr}^{-1}$ (Bianchi et al. 2012; DeVries et al. 2012, 2013). Note that the scaling reduction increases as nitrate concentrations decrease, facilitating a more balanced marine $\mathrm{N}$ cycle. This is an unsatisfying solution to a difficult problem, and suggests that climate impacts on the $\mathrm{N}$ cycle in our results should be regarded with caution. We return to the topic of the excessively large OMZs in section 3.

Iron cycling is driven by external inputs to the oceans from sediments and atmospheric deposition, balanced by loss of iron to the sediments (Moore and Braucher 2008). The atmospheric Fe deposition here is based on the dust climatology from Luo et al. (2003), assuming a constant $2 \%$ solubility. Inputs of iron to the oceans from atmospheric deposition and the sediments are held constant in these simulations. These simulations also include a time-varying atmospheric nitrogen deposition to the oceans based on Lamarque et al. (2010).

We examine the impacts of climate change on ecosystem behavior and biogeochemical tracers at the end of the twenty-first century using decadal mean values from the 2090s under the two RCPs, future scenarios RCP4.5 and RCP8.5 (Moss et al. 2010; van Vuuren et al. 2011). The RCP scenarios are distinguished by their respective top-of-the-atmosphere, globally averaged, radiative imbalance at year 2100. The RCP4.5 scenario assumes that greenhouse gas emissions stabilize by the middle of the twenty-first century with an anthropogenic radiative forcing of $4.5 \mathrm{~W} \mathrm{~m}^{-2}$ at year 2100 (Thomson et al. 2011). The CESM1(BGC) RCP4.5 simulation was run with prescribed atmospheric $\mathrm{CO}_{2}$ levels. The RCP8.5 scenario corresponds to a nominal anthropogenic forcing of $8.5 \mathrm{~W} \mathrm{~m}^{-2}$ at by 2100 , with emissions of $\mathrm{CO}_{2}$ following an exponential growth trajectory throughout the century (Riahi et al. 2011). The CESM1(BGC) RCP8.5 scenario examined here had a prognostic atmospheric $\mathrm{CO}_{2}$. In this simulation the global mean atmospheric $\mathrm{CO}_{2}$ concentration was nearly $200 \mathrm{ppm}$ higher than the RCP8.5 scenario values $(1150 \mathrm{ppm})$ at 2100 , indicating that ocean and land uptake of $\mathrm{CO}_{2}$ was weaker in CESM1(BGC) 
than in the reduced-complexity models used to construct the scenario.

The initial state of the CESM1(BGC) simulation was based on the initial state of the CCSM4 control (described by Gent et al. 2011). This simulation did not include the BEC ocean biogeochemistry. Initial ocean biogeochemical distributions were derived from a $1025-\mathrm{yr}$ offline, ocean-only simulation forced by a repeating 5 -yr cycle of high-frequency forcing data extracted from a fully coupled, CCSM4 simulation. Drifts in marine biogeochemical fluxes and tracer distributions were small at the end of this spinup, and ending conditions were used to initialize the CESM1(BGC) fully coupled, preindustrial control simulation that then was run for 1000 years (for additional details, see Lindsay et al. 2012, manuscript submitted to J. Climate). The model output for the 1990s examined here is from the 20C PROG experiment described by Lindsay et al. (2012, manuscript submitted to J. Climate), that included prognostic atmospheric $\mathrm{CO}_{2}$, full ocean and land biogeochemistry, and covered the period from 1850 to 2005 . The simulation includes the following transient forcings: greenhouse gases (with prognostic atmospheric $\mathrm{CO}_{2}$ and specified emissions), radiatively active aerosols, aerosol deposition to surface components, land use change, anthropogenic nitrogen deposition, and solar variability (Gent et al. 2011; Lindsay et al. 2012, manuscript submitted to J. Climate). This simulation was extended over the twenty-first century following the RCP8.5; the RCP4.5 simulation was branch off a comparable twentieth-century simulation with prescribed $\mathrm{CO}_{2}$.

Long et al. (2013, manuscript submitted to J. Climate) examine the time series of marine carbon fluxes over the twenty-first century and their controlling factors for the same integrations presented here, and they also examine a companion RCP8.5 simulation with prescribed atmospheric $\mathrm{CO}_{2}$ concentrations. The prognostic $\mathrm{CO}_{2} \mathrm{RCP} 8.5$ simulation had higher atmospheric $\mathrm{CO}_{2}$ concentrations and more warming than the prescribed $\mathrm{CO}_{2}$ simulation. The RCP4.5 pathway represents a stabilization scenario where atmospheric $\mathrm{CO}_{2}$ concentrations stabilize by the end of the century. Initially, mean sea surface temperature (SST) rises steadily, but stabilizes by $\sim 2060$ at about $1.8^{\circ} \mathrm{C}$ warmer than preindustrial SST. In contrast, in both RCP8.5 simulations, atmospheric $\mathrm{CO}_{2}$ concentrations rise exponentially throughout the twenty-first century, and mean SST steadily rises, increasing by $4^{\circ}$ and $3.4^{\circ} \mathrm{C}$ in the prognostic and prescribed $\mathrm{CO}_{2}$ simulations, respectively (Long et al. 2013, manuscript submitted to J. Climate).

\section{Results}

Results are divided into two sections focused on an evaluation of model performance for the 1990s, followed by an examination of climate change impacts on marine ecosystems and biogeochemistry at the end of the twentyfirst century.

\section{a. Biogeochemistry and ecosystem dynamics during the 1990s}

Temperature and salinity distributions simulated for the 1990s are generally in agreement with the World Ocean Atlas 2009 (WOA2009) observations (Locarnini et al. 2010; Antonov et al. 2010) with correlation coefficient values of $r=0.99$ and $r=0.84$ for annual mean surface temperature and salinity distributions (after log transformation; see also Danabasoglu et al. 2011; Bates et al. 2012). There is a small positive temperature bias in the global SST of $0.36^{\circ} \mathrm{C}$ and a negative salinity bias at the surface of $-0.29 \mathrm{ppt}$, with global RMS errors of $1.19^{\circ} \mathrm{C}$ and $0.930 \mathrm{ppt}$, respectively. The largest salinity biases are seen in the Arctic Ocean, with the model generally overestimating surface salinity. The positive temperature bias results in part from higher-thanobserved atmospheric $\mathrm{CO}_{2}$ concentrations in our simulation; furthermore, the CCSM4 had a largerthan-observed twentieth-century climate warming, even when forced with observed $\mathrm{CO}_{2}$ concentrations (Gent et al. 2011; Lindsay et al. 2012, manuscript submitted to J. Climate). The subsurface temperature and salinity fields in the upper ocean also reproduce the observed spatial patterns with a correlation coefficient of 0.98 at 200- and 300-m depth for temperature and 0.99 for salinity at these depths (after log transformation).

Variations in mixed layer depths have a strong influence on ocean biogeochemistry through their control of nutrient entrainment to surface waters, the light regime experienced by phytoplankton, and ventilation of subsurface waters. The CESM reproduces within $\sim 10 \mathrm{~m}$ the observed seasonal variations in mixed layer depths (calculated here as the depth where the density difference from surface waters exceeds $0.125 \mathrm{~kg} \mathrm{~m}^{-3}$ ). However, there are significant biases in a few key regions.

In the Southern Ocean, simulated wintertime mixed layer depths are much shallower than observed at midlatitudes, with the bias exceeding $300 \mathrm{~m}$ in some regions (Fig. 1). Similarly, the mixed layer depths during summer months are too shallow along much of the Antarctic Circumpolar Current (ACC), often by $20-40 \mathrm{~m}$ (Fig. 1). Biases in mixed layer depth of this magnitude can significantly impact the degree of light limitation (often iron and light colimitation) in this region (Krishnamurthy et al. 2007). Maximum mixed layer depths also have a shallow bias in the subtropical South Pacific and in the northwest Pacific Ocean. Otherwise, both maximum and minimum mixed layer depths tend to be deeper than observed at low to midlatitudes (Fig. 1). Mixed layer 


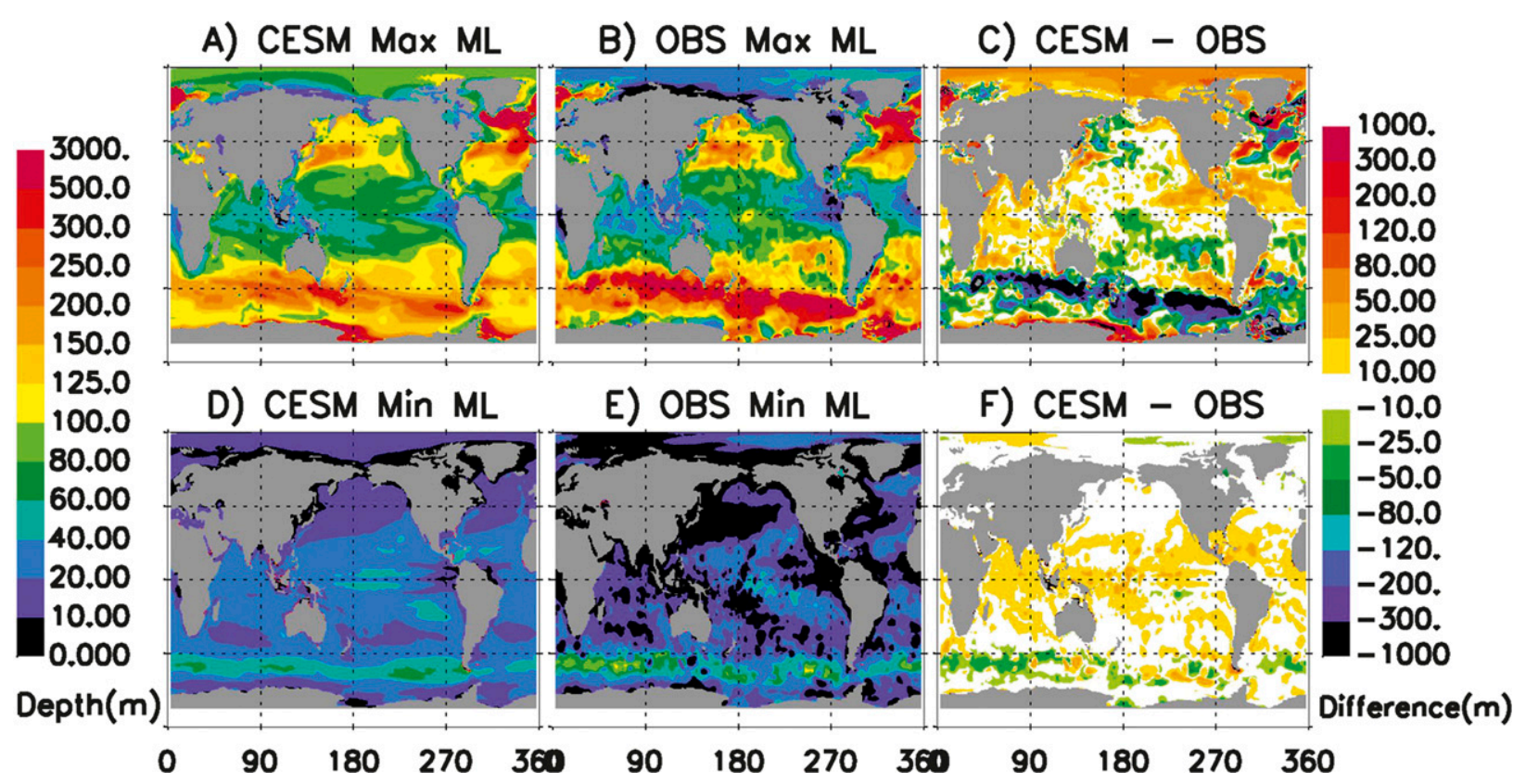

FIG. 1. Monthly mean (top) maximum and (bottom) minimum mixed layer depths from the CESM during the 1990s are compared with observed mixed layer depths from the WOA2009 (Locarnini et al. 2010; Antonov et al. 2010). Mixed layer depths were calculated from annual mean density fields as the depth where the density difference from surface waters exceeded $0.125 \mathrm{~g} \mathrm{~L}^{-1}$.

depths are too deep by $20-40 \mathrm{~m}$ over much of the Arctic Ocean.

These patterns influence the biogeochemistry in several ways. For instance, in the Southern Ocean, there is insufficient entrainment of nutrients to surface waters during winter, and ventilation and air-sea gas exchange are weaker than observed. This problem was welldocumented in previous versions of the CCSM (Thornton et al. 2009; Wang et al. 2012) and persists in the CESM. The shallow mixed layer depths during summer months cause an underestimation of light limitation in the model, depressing chlorophyll/C ratios. The shallow mixing also contributes to an overly strong drawdown of DIC in Southern Ocean surface waters (Long et al. 2013).

Observed basin-scale, macronutrient distributions are generally in agreement with the World Ocean Atlas datasets. A high correlation is seen between the annual mean model and WOA2009 fields (Garcia et al. 2010a) with correlation coefficient $r>0.8$ and variability similar to the observations (Fig. 2, all values log-transformed before computing statistics). The correlations with WOA2009 are similar at middepths, with the correlation coefficient ranging between 0.73 for nitrate and 0.90 for silicate at $410-\mathrm{m}$ depth. The correlations for upperocean iron $(0-50 \mathrm{~m})$ and surface chlorophyll are somewhat lower (Fig. 2). For iron, the observational database is still quite sparse and does not yet provide a true climatology (Moore and Braucher 2008). We examine the marine iron cycle in these simulations in more detail in
Misumi et al. (2013). These correlations for nutrients are similar to previous work in the CCSM (Moore and Braucher 2008; Doney et al. 2009b).

Surface macronutrient biases are seen in the equatorial Pacific, where the high-nitrate/phosphate waters extend too far north and south of the equator and too far to the west (Fig. 3). Also, note the low nutrient bias in the Southern Ocean and in the subarctic North Pacific. The low nutrient concentrations in these regions are partly due to the shallow wintertime mixed layer biases in both regions (Fig. 1) and to a generally weak vertical exchange between the surface ocean and the ocean interior. The model captures the observed minimum in surface phosphate concentrations in the subtropical North Atlantic (Fig. 3).

The CESM1(BGC) reproduces the observed basinscale surface chlorophyll distributions (Figs. 2, 4). In the Southern Ocean, the regions around Kerguelen and South Georgia Islands exhibit blooms driven by the strong sedimentary iron source. These island blooms are somewhat more intense in the model than in the satellite data. High chlorophyll concentrations, associated with sedimentary iron inputs, are also seen in Antarctic coastal waters and on the Bering Sea shelf (Fig. 4). Simulated chlorophyll concentrations tend to be too high at low to midlatitudes, and the elevated chlorophyll associated with the equatorial upwelling tongue in the equatorial Pacific also has a positive bias and extends too far to the west. 


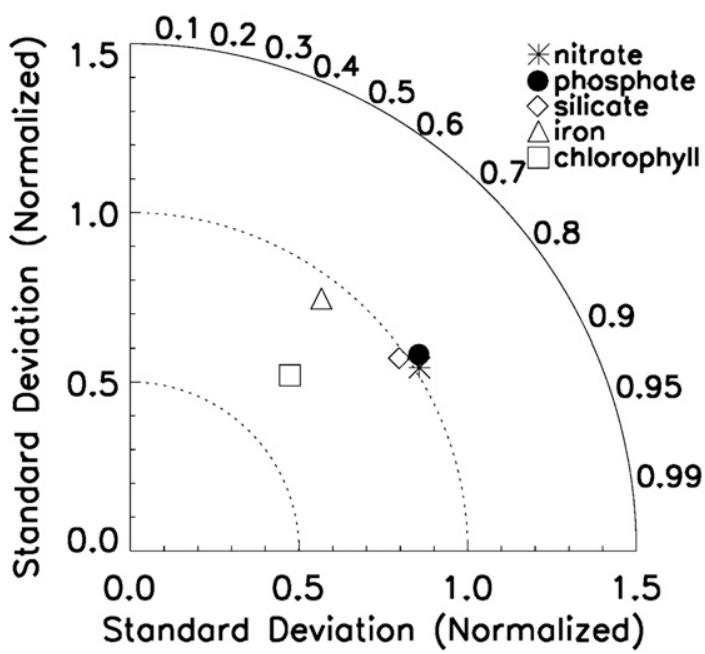

FIG. 2. CESM simulated annual mean surface nutrient and chlorophyll concentrations for the 1990s are compared with observational datasets in a Taylor diagram (Taylor 2001). Surface macronutrient concentrations are compared with the WOA2009 (Garcia et al. 2010a). Chlorophyll concentrations are compared with the annual mean Sea-viewing Wide Field-of-view Sensor (SeaWiFS) satellite chlorophyll climatology, and dissolved iron concentrations in the upper $50 \mathrm{~m}$ are compared with the observational database compiled by Moore and Braucher (2008). All values were log-transformed before statistical calculations.

Chlorophyll concentrations are too high throughout much of the Arctic Ocean because of an intense summer diatom bloom (Fig. 4). Under the current climate, heavy ice cover leads to strong light limitation of growth and prevents phytoplankton blooms in the central Arctic. However, the CESM simulated percent sea ice cover is underestimated during summer months (Fig. 5). The mean August ice concentration north of $80^{\circ} \mathrm{N}$ in the model is $83 \%$, while it is $91 \%$ in the observations (with similar underestimations of percent ice cover in June and July). The negative bias in sea ice cover allows phytoplankton to grow throughout the central Arctic Ocean during the summer. Some of the high-chlorophyll blooms observed in Arctic coastal waters are missing in the CESM simulation, likely influenced by the lack of river nutrient inputs in the model, although riverine dissolved organic matter inputs may lead the satellite estimate to be biased high (Figs. 4, 5).

Growth over most of the ocean is limited by either nitrogen or iron for the diatom and small phytoplankton groups (Fig. 6). The diazotrophs are limited mainly by phosphorus in the Atlantic and Indian basins and by iron in the Pacific, consistent with previous BEC results (Moore et al. 2004; Moore and Doney 2007). This is perhaps not surprising as the biogeochemical model is similar to these previous studies, although there have been major modifications to the ocean circulation model
(Danabasoglu et al. 2011). The strong sedimentary iron source in the western, low-latitude Pacific leads to $\mathrm{P}$ limitation of the diazotrophs. The CESM reproduces the known high nitrate, low chlorophyll (HNLC) regions because of iron limitation in the subarctic North Pacific, the equatorial Pacific, and the Southern Ocean (Fig. 6). However, the subarctic North Pacific HNLC zone has a smaller spatial extent than observed, while the equatorial Pacific HNLC zone extends too far north and south of the equator (see Fig. 3). Nutrient "replete" areas are where the concentration of nutrients is high enough to support growth rates $>90 \%$ of the maximum potential growth rate. This primarily occurs where light limitation and/or strong grazing pressure prevents utilization of the nutrients.

Darker color shades in Fig. 6 indicate areas with stronger nutrient limitation of growth. In these areas growth rates are reduced by more than $50 \%$ from their potential maximum values given ambient temperature and light in the surface ocean (i.e., where ambient concentrations for the limiting nutrient are below the halfsaturation concentration). The diatoms are relatively inefficient at nutrient uptake compared with the small phytoplankton (higher half-saturation constants for nutrient uptake). The diatoms are strongly $\mathrm{N}$-limited throughout much of the lower-latitude oceans with more modest $\mathrm{N}$ stress at higher latitudes, while the small phytoplankton are strongly limited only in the most oligotrophic areas. For all three phytoplankton groups, weaker iron limitation is seen along the equator in the eastern Pacific than regions just to the north and south (Fig. 6). This is due to the upwelling of iron at the equator and modestly higher iron concentrations in surface waters.

A long-standing problem in previous versions of the CCSM is a large positive bias in the volume and spatial extent of the ocean oxygen minimum zones (OMZs). Figure 7 compares simulated oxygen concentrations with the WOA2009 climatology (Garcia et al. 2010b). $\mathrm{OMZ}$ waters are defined here as $\mathrm{O}_{2}$ concentrations $<$ $20.0 \mu \mathrm{M}$ (Paulmier and Ruiz-Pino 2009). Over the upper ocean (150-1041 m), the spatial extent of OMZ waters is strongly overestimated in the Indian and eastern Pacific basins, and the volume of OMZ waters is 3.2 times larger than observed in the WOA2009 (Figs. 7a,b). There are also OMZ waters in the Atlantic basin, where concentrations below $20.0 \mu \mathrm{M}$ are rarely observed. The problem is particularly bad in the middle of this depth range, 364-670 m, where the OMZ waters encompass the entire eastern equatorial Pacific Ocean and the northern Indian Ocean (Figs. 7c,d). Over this depth range the volume of $\mathrm{OMZ}$ waters is 3.8 times larger than observed. Globally, the volume of these waters is 2.9 times the observed volume. 
A) CESM Annual Nitrate

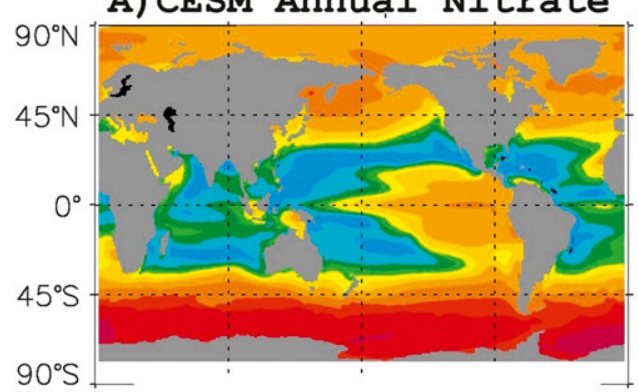

C) WOA Annual Nitrate

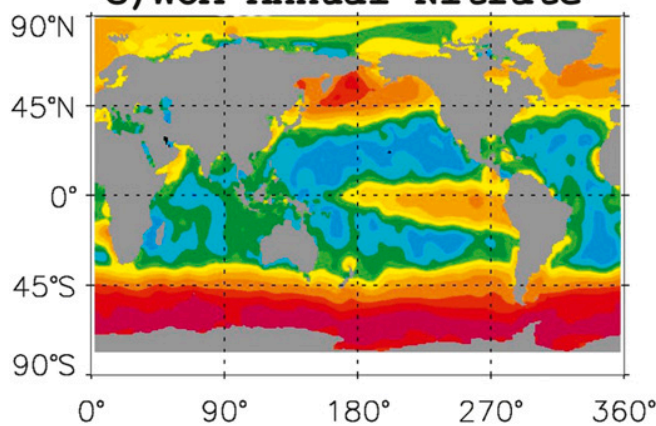

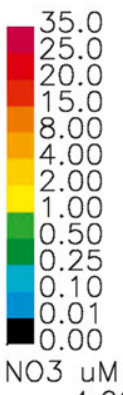

B) CESM Annual Phosphate

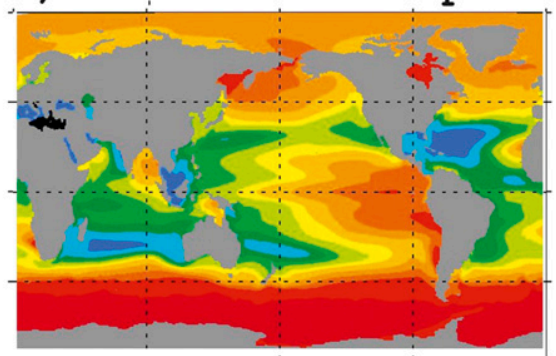

D) WOA Annual Phosphate

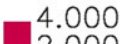

2.000

1.500

0.800

0.600

0.400

0.300

0.200

0.150

0.100

0.050

0.005

0.000

PO4 uM

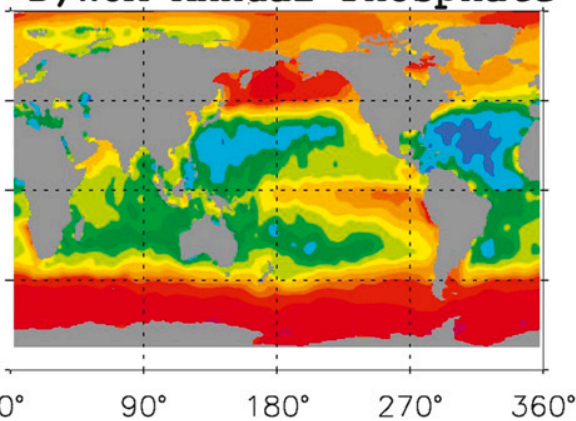

FIG. 3. CESM simulated annual mean surface nitrate and phosphate concentrations for the 1990s are compared with observations from the WOA2009 (Garcia et al. 2010a).

The CESM(BGC) captures the large-scale spatial patterns in oxygen concentrations, but with negative bias over much of the ocean (Fig. 7). Oxygen concentrations are underestimated throughout the tropics and within the subtropics in the Northern Hemisphere. Oxygen concentrations are also underestimated in the subarctic North Pacific and the Arctic Ocean. The mean biases over these depth ranges are $-25 \mu \mathrm{M}(150-1041 \mathrm{~m})$ and $-28 \mu \mathrm{M}(373-670 \mathrm{~m})$. The whole-ocean mean bias for oxygen is $-8 \mu \mathrm{M}$ (Table 1 ). Even relatively small negative biases in mean ocean oxygen concentrations may have a disproportionately large impact on the oxygen minimum zones (Bianchi et al. 2012). The response of OMZ volume to climate change is driven by complex interactions between the processes controlling circulation and ventilation, and those controlling the sinking organic matter flux and remineralization. An expansion of the suboxic $\mathrm{O}_{2}$ water volume has not been seen in all ocean-climate simulations to date, even though global mean oxygen concentrations decline (see Gnanadesikan et al. 2012). Dietze and Loeptian (2013) examine this problem in detail with several different models and suggest much of the problem may be due to poor simulation of the Equatorial Intermediate Current System, which may be important for ventilating the $\mathrm{OMZ}$ regions. Getzlaff and Dietze (2013) show that mimicking the transport of these zonal jets with increased isopycnal mixing can greatly reduce oxygen biases similar to those in the CESM.
Ongoing work is seeking to reduce these $\mathrm{O}_{2}$ biases and suggests that, in many regions, the bias results from complex interactions between biogeochemistry and physics. In the Arctic, low $\mathrm{O}_{2}$ is likely driven by the higher-than-observed biological productivity and export, resulting from the negative bias in summer sea ice cover. In the North Pacific, there is weak ventilation of the intermediate waters, with little formation of North

\section{A) CESM-BEC Annual Chlorophyll}

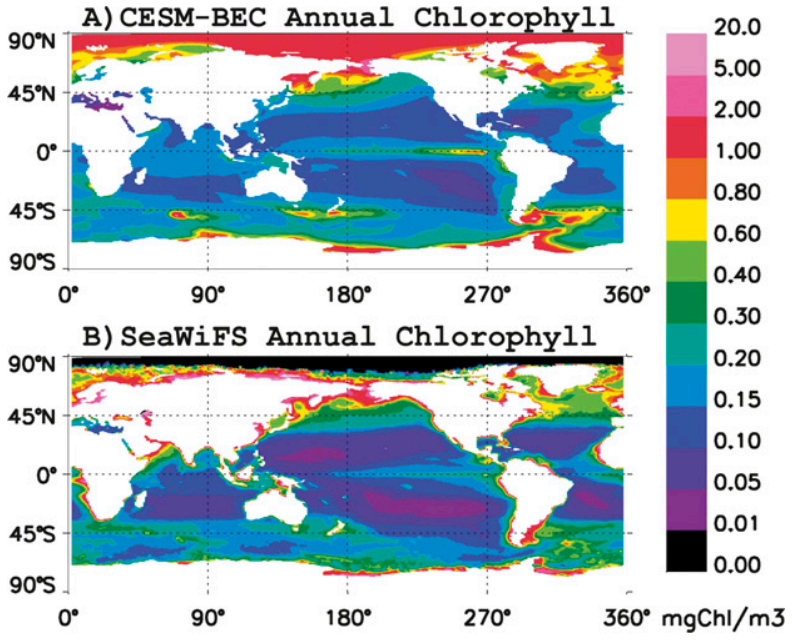

FIG. 4. CESM simulated annual mean surface chlorophyll concentrations for the 1990s are compared with climatological estimates from the SeaWiFS satellite sensor. 
A) CESM \% Sea Ice Cover August

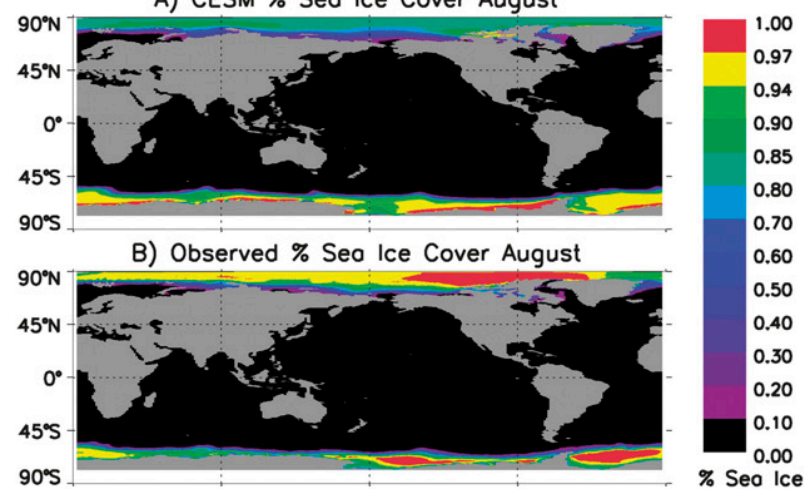

FIG. 5. CESM simulated monthly mean percent sea ice cover during August for the 1990s is compared with observed climatological August percent sea ice cover from Comiso (1999).

Pacific Intermediate Water. This may be in part because of insufficient tidally driven mixing in the northwest Pacific and the absence in the model of some physical processes, such as Langmuir mixing and inertial waves, that make significant contributions to vertical mixing and ventilation, particularly at higher latitudes. The absence of these processes likely plays a role in the shallow bias in wintertime mixed layer depths (Fig. 1). At lower latitudes, ventilation of the subsurface waters by isopycnal mixing appears to be too weak, partially contributing to the low-oxygen biases. Weak representation of the Equatorial Intermediate Currents may also play a role (Dietze and Loeptien 2013; Getzlaff and Dietze 2013).

While the circulation dynamics controlling ventilation make important contributions to the OMZ biases, biogeochemical factors also play a strong role. The most important of these is deficiencies in the prescribed remineralization curves as a function of depth applied to sinking organic matter. The mineral ballast model proposed by Armstrong et al. (2002) divides the sinking POM into two classes: one class strongly associated with mineral ballast types (including lithogenic particles, biogenic silica, and calcium carbonate), where the POM remineralizes according to the prescribed (deeper) remineralization curves for the ballast material, and a second class, the "soft" POM that remineralizes at shallower depths according to an exponential curve with a fixed length scale. Most of the POM leaving the euphotic zone $(>90 \%)$ is in this soft class.

The exponential curve with fixed length scale in CESM for the soft POM contributes to the biases in the subsurface oxygen and nutrient concentrations. The global mean vertical profiles for key biogeochemical tracers are shown in Fig. 8, compared with the observed profiles from the WOA2009 (Garcia et al. 2010a) and

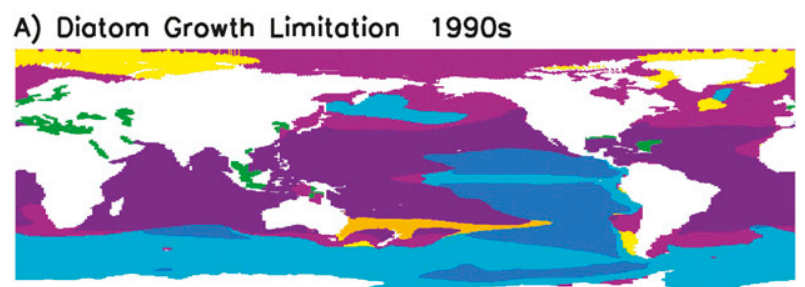

Nitrogen $57.70 \%$, Iron $37.90 \%$, Silico $2.255 \%$, Phosphorus $2.137 \%$ Replete $0.000 \%$

\#itrogen Elron \#Phosphorus ESilicon Temperature Replete

B) Small Phytoplankton Growth Limitation

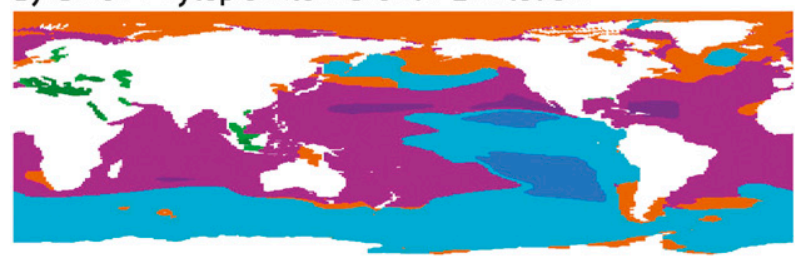

Nitrogen $50.82 \%$, Iron $38.63 \%$, Phosphorus $0.821 \%$ Replete $9.713 \%$

\section{C) Diazotroph Growth Limitation}

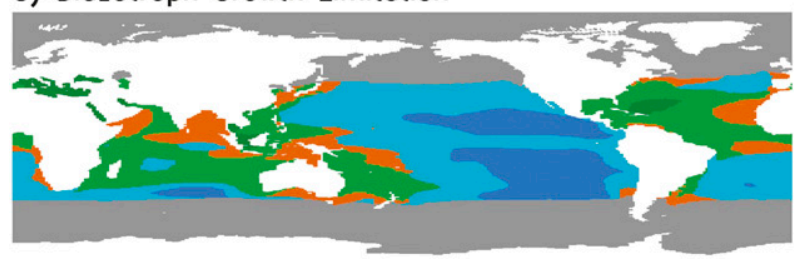

Nitrogen $0.000 \%$, Iron $38.18 \%$, Phosphorus $21.74 \%$

Replete $9.144 \%$, Temperoture $30.92 \%$

FIG. 6. The factor most limiting growth over the annual time scale during the 1990s is displayed. Darker shade of each color indicates stronger nutrient limitation (growth reduced by $>50 \%$ from maximum). Nutrient replete means nutrient concentrations are sufficient for the phytoplankton to grow at $>90 \%$ of their maximal rates.

Global Data Analysis Project (GLODAP) datasets (for DIC and alkalinity; Key et al. 2004). Note the positive biases in phosphate and DIC and the negative bias for $\mathrm{O}_{2}$ at middepths $(\sim 500 \mathrm{~m})$. There is excessive remineralization of organic matter at these depths contributing to the $\mathrm{O}_{2}$ biases. This also results in a flux of organic matter to the deep ocean that is too small, driving negative biases in DIC and phosphate and positive oxygen biases in deep waters. Kriest and Oschlies (2008) suggest that a length scale increasing with depth provides a better match to observed nutrient distributions than a constant length scale. Applying a remineralization curve with this property to the soft POM would likely reduce these biases.

There are also some strong biases in the vertical profile of simulated alkalinity in the model. Long et al. (2013) documented a substantial negative bias for alkalinity in surface waters and discuss its implications for air-sea 


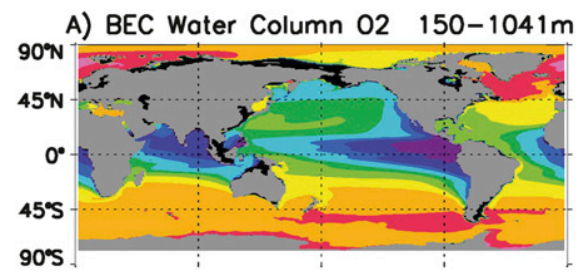

B) WOA2009 Water Column 02

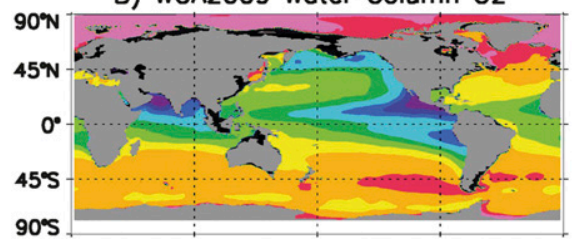

C) BEC Woter Column $02 \quad 364-671 \mathrm{~m}$
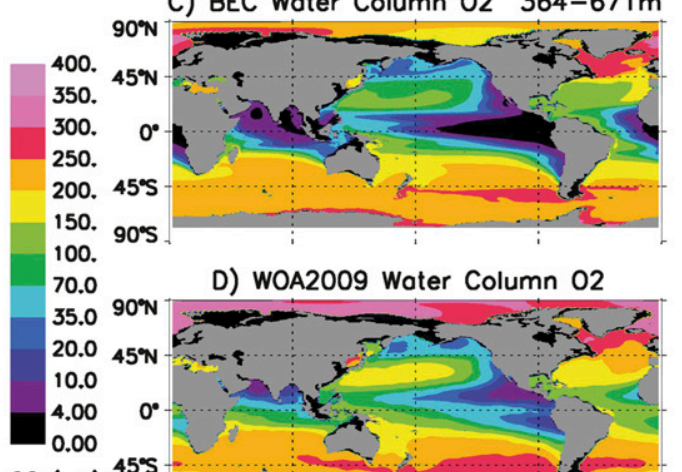

02 (uM)
D) WOA2009 Woter Column 02

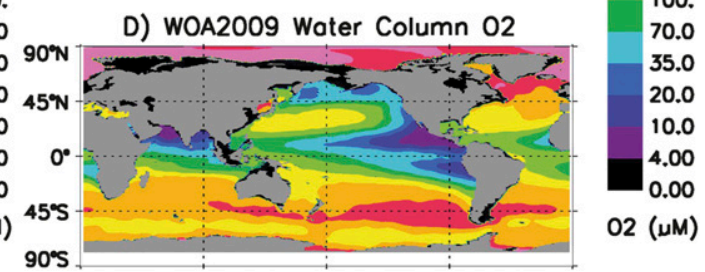

FIG. 7. Simulated annual mean oxygen concentrations for the 1990s are compared with observed concentrations from the WOA2009 (Garcia et al. 2010b) averaged over the depth range (a),(b) from 150 to $1041 \mathrm{~m}$ and (c),(d) 363 to $670 \mathrm{~m}$.

$\mathrm{CO}_{2}$ fluxes. Here we can see that alkalinity biases are driven by deficiencies in the prescribed remineralization curve for sinking $\mathrm{CaCO}_{3}$, which leads to large negative bias in the upper water column and a positive bias in the lower water column (Fig. 8f). The rain ratio (sinking $\mathrm{CaCO}_{3} /$ sinking POC) leaving the euphotic zone at $100 \mathrm{~m}$ is reasonable at $\sim 0.09 \mathrm{molC}(\mathrm{mol} \mathrm{C})^{-1}$ (recent estimates $\sim 0.07-0.11$; Lee 2001; Sarmiento et al. 2002; Jin et al. 2006). Thus, the problem seems to be the prescribed remineralization curve driving remineralization too deep in the water column. Currently, it is not computationally feasible to conduct a large number of simulations thousands of years in length to optimally tune the parameter values that control remineralization in the deep ocean. New fast-solver, optimization techniques have promise for addressing this difficulty in the near future (e.g., Kwon and Primeau 2006).

Simulated nitrate concentrations are below observed concentrations over much of the water column (Fig. 8).
This is the result of small imbalances in the $\mathrm{N}$ cycle sources and sinks, which, when integrated over our long spinup and preindustrial simulations, lead the ocean to lose some fixed $\mathrm{N}$ (even with our scaling factor reducing the denitrification loss). At the end of the preindustrial era, the oceans were nearly balanced, losing $\sim 11 \mathrm{TgN} \mathrm{yr}^{-1}$.

Globally integrated nitrogen fixation during the 1990s averages $174 \mathrm{TgN} \mathrm{yr}^{-1}$ and water column denitrification averages $193 \mathrm{TgN} \mathrm{yr}^{-1}$ (Table 1, Fig. 9). There is increasing nitrogen input from rising atmospheric deposition of anthropogenic $\mathrm{N}$ to the oceans (reaching $\sim 30 \mathrm{TgN} \mathrm{yr}^{-1}$ by the $1990 \mathrm{~s}$; Lamarque et al. 2010), leading to a small imbalance, with the oceans gaining $\sim 10 \mathrm{TgN} \mathrm{yr}^{-1}$ during the 1990s (Table 1). Increasing atmospheric $\mathrm{N}$ deposition will be partially offset by reductions in $\mathrm{N}$ fixation because of a lowering of surface $\mathrm{P}$ and Fe concentrations (Krishnamurthy et al. 2007, 2009). The model does not include the $\mathrm{N}$ source from riverine

TABLE 1. Key globally integrated biogeochemical fluxes are shown from the end of the preindustrial control simulation, the 1990 s, and the 2090s under the RCP4.5 and RCP8.5 scenarios.

\begin{tabular}{|c|c|c|c|c|}
\hline Flux or Concentration & Preindustrial & $1990 \mathrm{~s}$ & RCP4.5 2090s & RCP8.5 2090s \\
\hline Gross primary production $\left(\mathrm{PgC}_{\mathrm{gr}}{ }^{-1}\right)$ & 55.6 & 56.1 & 54.9 & 52.9 \\
\hline Sinking POC at $100 \mathrm{~m}\left(\mathrm{PgC}^{-1}\right)$ & 8.10 & 8.07 & 7.66 & 7.00 \\
\hline Sinking $\mathrm{CaCO}_{3}$ at $100 \mathrm{~m}\left(\mathrm{PgC} \mathrm{yr}^{-1}\right)$ & 0.762 & 0.752 & 0.723 & 0.726 \\
\hline Rain ratio $\left(\mathrm{CaCO}_{3} / \mathrm{POC}\right) 100 \mathrm{~m}$ & 0.094 & 0.093 & 0.094 & 0.10 \\
\hline Nitrogen fixation $\left(\mathrm{TgN} \mathrm{yr}^{-1}\right)$ & 174 & 173 & 159 & 141 \\
\hline Nitrogen deposition $\left(\mathrm{TgN} \mathrm{yr}^{-1}\right)$ & 6.70 & 30.0 & 21.3 & 30.9 \\
\hline Denitrification $\left(\mathrm{TgN} \mathrm{yr}^{-1}\right)$ & 192 & 193 & 187 & 185 \\
\hline $\mathrm{N}$ cycle imbalance* $\left(\mathrm{TgN}^{-1} \mathrm{rr}^{-1}\right)$ & -11.3 & 10 & -6.7 & -13.1 \\
\hline Air-sea $\mathrm{CO}_{2}$ flux $\left(\mathrm{PgC} \mathrm{yr}^{-1}\right)$ & -0.0693 & 2.19 & 1.89 & 4.94 \\
\hline Diatom primary production (\%) & 38 & 37 & 35 & 29 \\
\hline Mean ocean oxygen $(\mu \mathrm{M})$ & 170 & 167 & 162 & 157 \\
\hline OMZ volume $\left(\times 10^{16} \mathrm{~m}^{3} ;<20 \mu \mathrm{M}\right)^{* *}$ & 3.7 & 3.8 & 4.4 & 4.6 \\
\hline
\end{tabular}

$*$ Equals $+\mathrm{N}$ deposition $+\mathrm{N}$ fixation - denitrification.

** WOA2009; mean $\mathrm{O}_{2}=175 \mu \mathrm{M}$ and $\mathrm{OMZ}$ volume $=1.31 \times 10^{16} \mathrm{~m}^{3}$. 

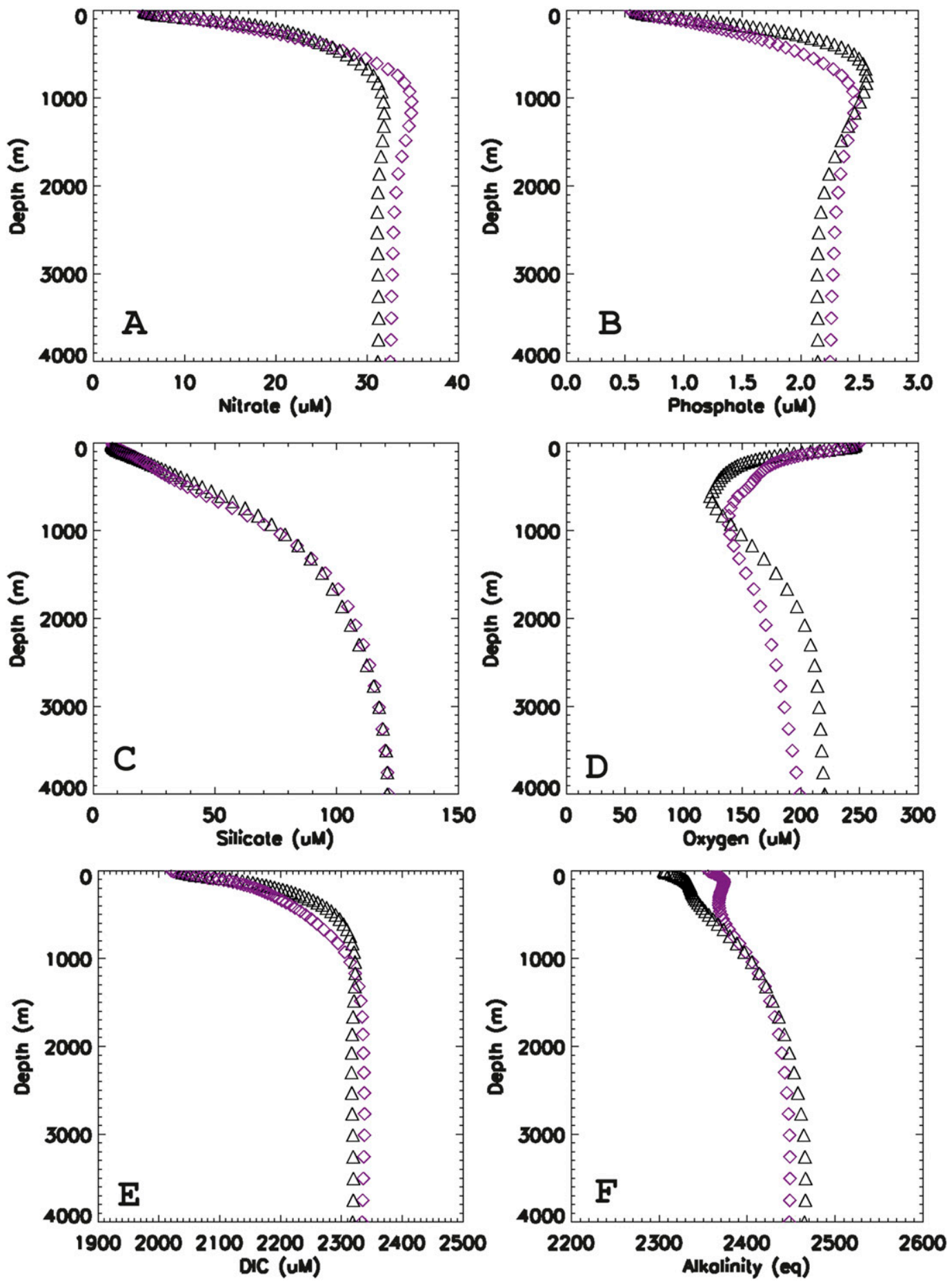

FIG. 8. Globally averaged vertical profiles of key biogeochemical tracers are shown from the CESM simulation of the 1990s (black triangles) compared with observations (purple diamonds) from the WOA2009 (Garcia et al. 2010a) and GLODAP datasets (Key et al. 2004).

input or the sedimentary losses due to denitrification and burial. The nitrogen fixation rate is on the high end of recent estimates, which range from $\sim 100$ to $200 \mathrm{TgN} \mathrm{yr}^{-1}$ (e.g., Karl et al. 2002; Gruber 2004; Moore and Doney
2007). The high rates of $\mathrm{N}$ fixation result from the high rates of water column denitrification (see Moore and Doney 2007 for discussion of the feedbacks between these processes). The water column denitrification exceeds 


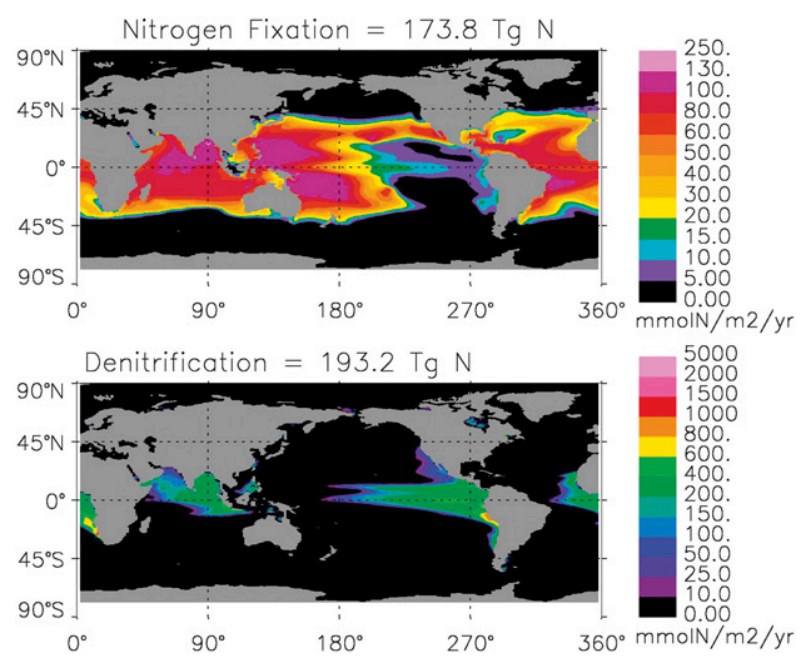

FIG. 9. Annual mean nitrogen fixation and water column denitrification simulated by the CESM1(BGC) for the 1990s.

recent estimates, which range from 66 to $150 \mathrm{TgN} \mathrm{yr}^{-1}$ (Codispoti et al. 2001; Gruber 2004; DeVries et al. 2012; Bianchi et al. 2012) even with our ad hoc scaling factor reducing denitrification by more than $50 \%$.

The scaling down of denitrification allows the marine nitrogen cycle to nearly balance, but because of the use of this scaling factor and the large biases in simulated oxygen distributions, the current version of CESM cannot be reliably used to study these $\mathrm{N}$ cycle processes in the context of climate change. Similarly, changes in ocean oxygen concentrations due to climate change must viewed with some caution because of the poor simulation of $\mathrm{O}_{2}$ distributions in the current era. Improvements are underway for future releases of the CESM.

\section{b. Impacts of climate change on marine ecosystems and biogeochemistry}

We next compare our results from the 1990s with the end of the twenty-first century (2090s) under the RCP4.5 and RCP8.5 scenarios to examine the impacts of climate change on marine ecosystems and upper-ocean biogeochemistry. Key globally integrated biogeochemical fluxes are summarized in Table 1 for the different time periods and RCP scenarios. There is little change in the upper-ocean carbon fluxes between the end of the preindustrial era and the 1990s (Table 1). However, by the end of the twenty-first century, climate change significantly impacts ocean biogeochemistry, in particular leading to a reduction in the export of organic matter out of surface waters. Globally integrated export production is reduced by $5 \%$ under the RCP 4.5 scenario and by $13 \%$ under the RCP8.5 scenario (Table 1 ). Net primary production declines by $2.1 \%$ and $5.7 \%$ under these two scenarios, respectively. These climate change-driven perturbations to primary and export production are well outside the natural variability seen in these fluxes in the preindustrial control simulation (see Long et al. 2013, manuscript submitted to J. Climate). The stronger

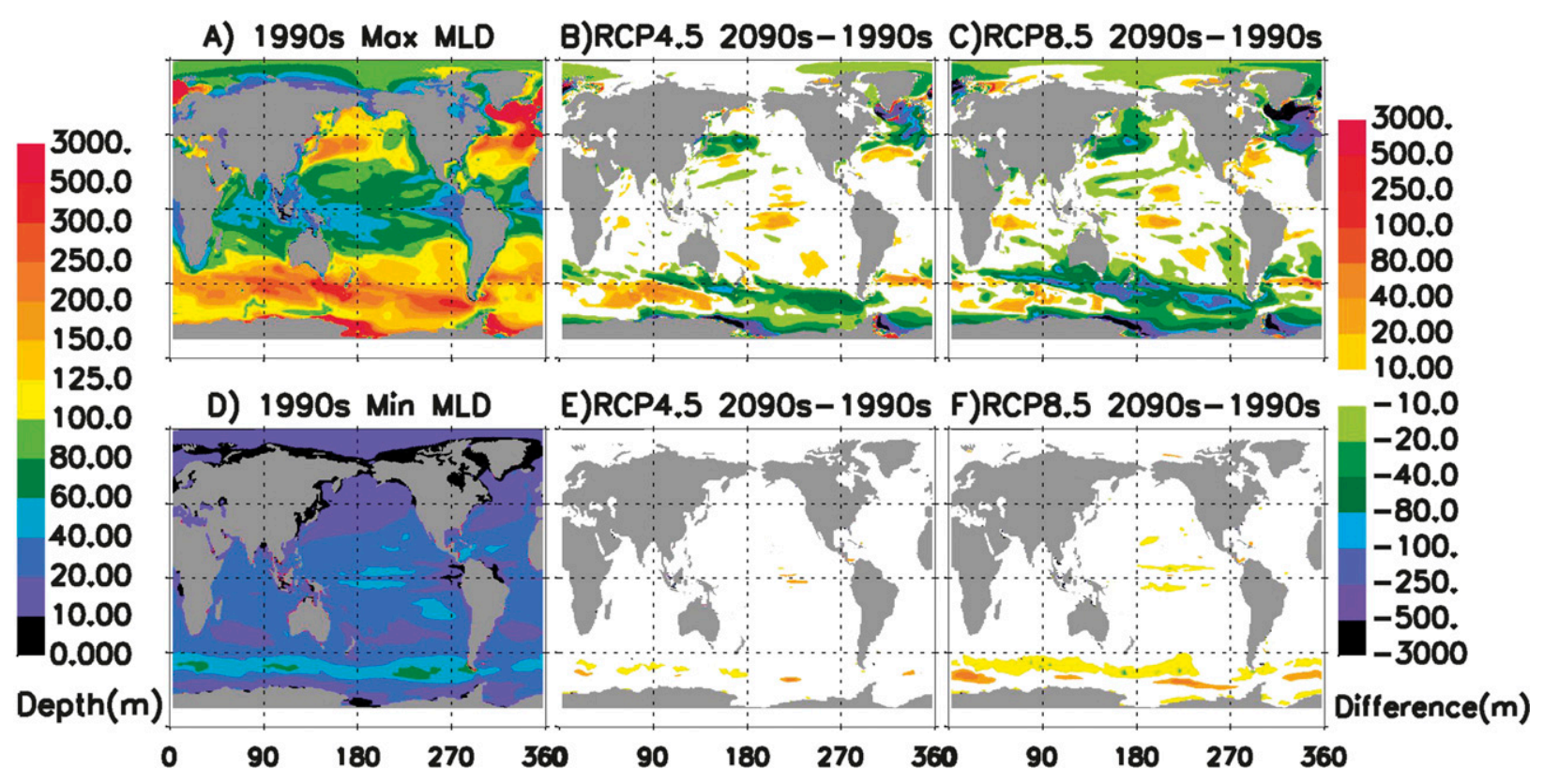

FIG. 10. Monthly mean maximum and minimum mixed layer depths from the CESM during the 1990s are compared with simulated mixed layer depths from the 2090s under the RCP4.5 and RCP8.5 scenarios. Mixed layer depths were calculated as the depth with a density difference from surface waters $>0.125 \mathrm{~g} \mathrm{~L}^{-1}$. 


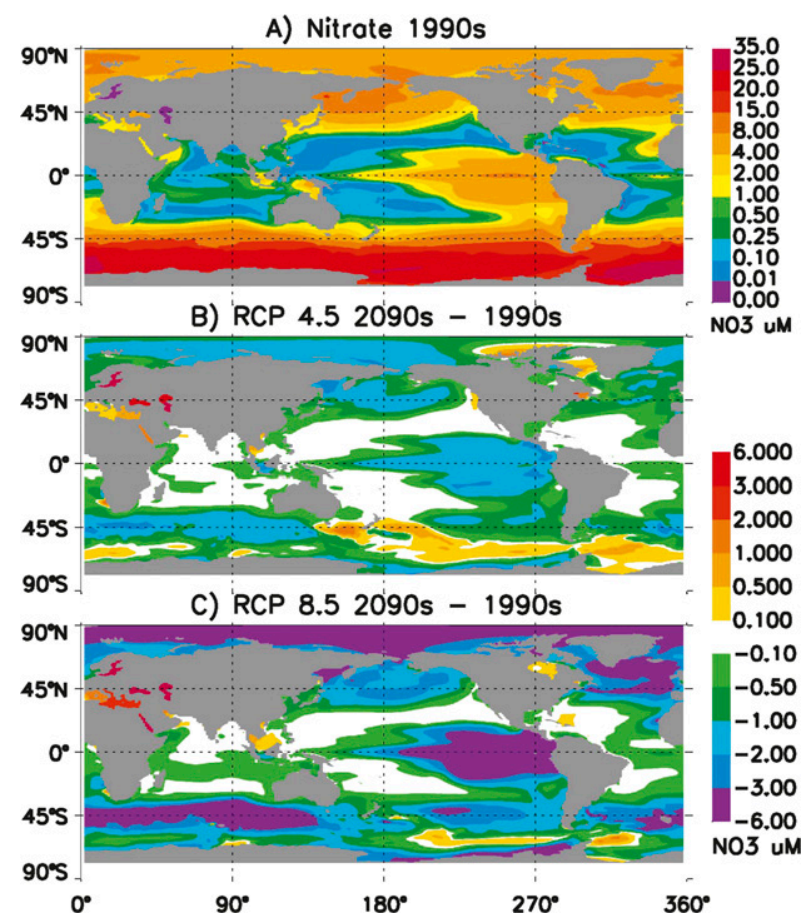

FIG. 11. CESM simulated annual mean surface nitrate concentrations from the 1990s are compared with simulated values for the 2090s under the RCP4.5 and RCP8.5 scenarios.

warming in RCP8.5, driven by the higher greenhouse gas emissions, leads to stronger biogeochemical impacts than under the RCP4.5 scenario. There is an expansion of the low-oxygen water volume in the future scenarios and a decrease in the mean ocean oxygen concentration, by $10 \mu \mathrm{M}$ under RCP8.5 (Table 1 ).

There is strong warming of upper-ocean waters by the 2090s under the RCP8.5 scenario, leading to stronger vertical stratification and a shoaling of wintertime surface mixed layer depths, mainly in the mid to high latitudes (Fig. 10). Maximum monthly mixed layer depths decline over much of the Southern Ocean, the northwest Pacific, and the high-latitude North Atlantic by $\sim 40$ $100 \mathrm{~m}$, relative to the 1990s (Fig. 10). In the North Atlantic, around southern Greenland there is a collapse in deep convective mixing during winter months, and maximum mixed layer depths decline by $>500 \mathrm{~m}$. Surface salinity reductions play a role in the increasing stratification in the Northern Hemisphere. The increased vertical stratification, its spatial patterns, and driving factors are very consistent with those seen in the CMIP3 climate models, as a result of climate warming under the SRES A2 scenario (Capotondi et al. 2012). Similar, but weaker, reductions in winter mixed layer depths are seen in the RCP4.5 simulation, with large reductions in the North Atlantic and portions of the Weddell and

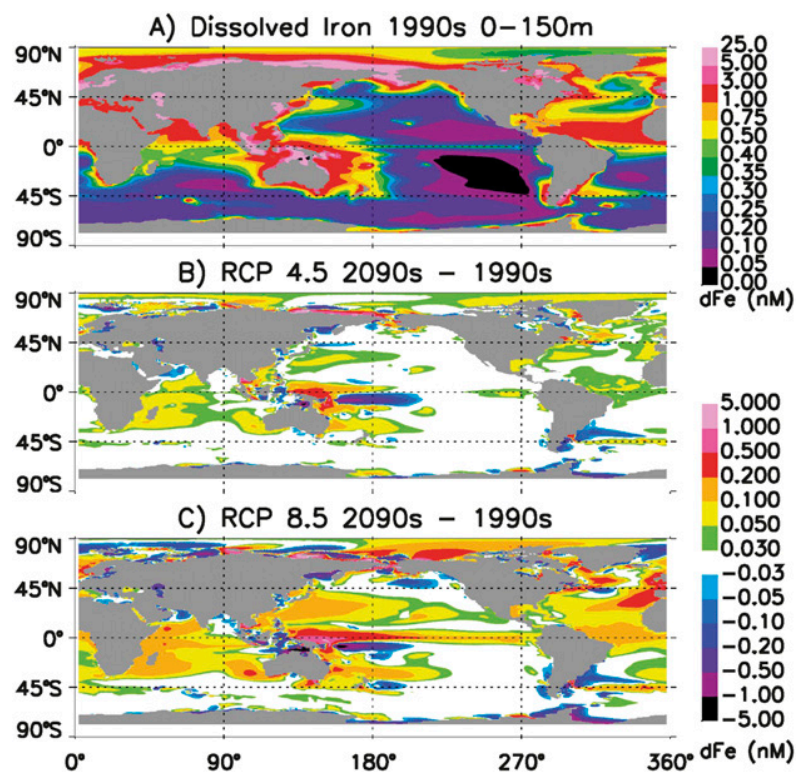

FIG. 12. CESM simulated upper-ocean annual mean dissolved iron concentrations $(0-150 \mathrm{~m})$ from the 1990 s are compared with concentrations from the 2090s under the RCP4.5 and 8.5 scenarios.

Ross seas. There is little in change in the minimum monthly mixed layer depths under either scenario, other than a modest deepening in the Southern Ocean (Fig. 10) associated with an intensification and poleward shift in the westerly winds (not shown).

The upper-ocean warming and increased stratification lead to a weakening of the nutrient flux to surface waters and some dramatic decreases in surface macronutrient concentrations (Fig. 11). Surface nitrate concentrations decline in nearly every region of the globe, with the largest decreases in the equatorial Pacific, over much of the Southern Ocean along the ACC, the high-latitude North Atlantic and the Arctic Ocean (Fig. 11). The highnitrate region in the tropical Pacific shrinks dramatically (Fig. 11). Similar reductions are seen in surface phosphate concentrations (not shown). The spatial patterns are very similar in the RCP4.5 and 8.5 simulations, with larger reductions under RCP8.5.

Upper-ocean dissolved iron concentrations increased over much of the ocean by the end of the century under RCP8.5 and more modestly under RCP4.5 (Fig. 12). These shifts were largely driven by the decreasing concentrations of surface nitrate and phosphate. As these macronutrients become more limiting for phytoplankton growth, there is less biological uptake of iron in surface waters. There is also less export production, which results in decreasing scavenging losses for dissolved iron within and below the euphotic zone. Away from the major dust deposition regions, biological particles dominate the scavenging loss for iron. Thus, we see increased upper-ocean 


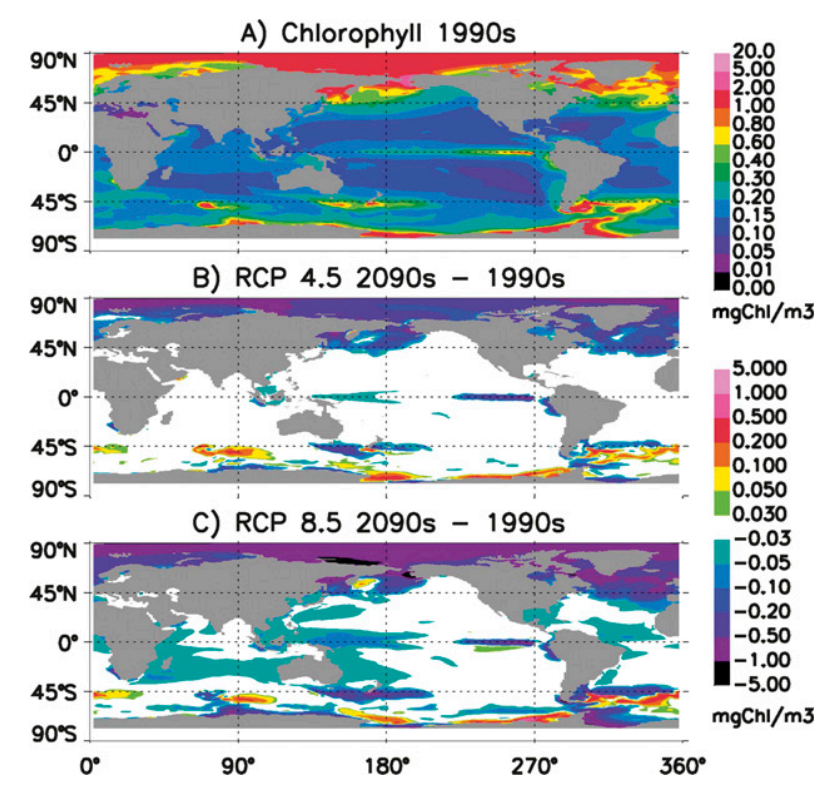

FIG. 13. As in Fig. 11, but for surface chlorophyll concentrations.

iron concentrations throughout the tropics and subtropics, often exceeding a $0.1 \mathrm{nM}$ increase averaged over the top $150 \mathrm{~m}$ under RCP8.5 (Fig. 12). The increased iron concentrations in these regions lead to increased lateral transport of iron into the adjacent HNLC regions. There are small increases in iron concentration in parts of the subpolar North Pacific and in the Southern Ocean (Fig. 12), but biological uptake generally keeps iron concentrations low in these regions. Some of the largest iron shifts are seen under RCP8.5 in the western equatorial Pacific, where declining surface nitrate leads to large reductions in the biological uptake in surface waters and reductions in the export production. The reduction in export leads to reduced scavenging of iron and enhanced lateral transport of dissolved iron to the eastern equatorial Pacific within the Equatorial Undercurrent. Some of this iron is then upwelled, leading to increased dissolved iron concentrations across the equatorial Pacific (Fig. 12) and increased productivity and export in the eastern equatorial Pacific (see below). Recall that in these simulations, the external iron inputs to the oceans from atmospheric deposition and sedimentary sources have been held constant. In reality, the dust and iron inputs from the atmosphere are likely to change with climate, although there is uncertainty about even the sign of this change (e.g., Mahowald and Luo 2003; Mahowald et al. 2010).

The reduced macronutrient inputs lead to decreases in phytoplankton biomass and chlorophyll (Fig. 13). The largest decreases in chlorophyll concentrations are seen in the Arctic Ocean, where decreasing sea ice cover over the twenty-first century (Vavrus et al. 2012) leads to a longer growing season and depletion of surface nutrients (Figs. 11, 13). There are a few regions in the Southern Ocean where chlorophyll concentrations increase, partly driven by declines in sea ice cover at higher latitudes, as well as through increased lateral iron inputs, as productivity and export decline in adjacent lower-latitude regions (Figs. 12, 13). Chlorophyll concentrations can change with phytoplankton biomass or in response to changing chlorophyll/C ratios due to photoadaptation. Given the minimal changes in minimum (summer season) mixed layer depths (Fig. 10), the declines in surface macronutrient concentrations (Fig. 11), and the increasing nutrient stress (see below), the changes in chlorophyll in Fig. 13 are largely driven by the changes in phytoplankton biomass.

There is a general expansion of the nitrogen-limited areas and a shrinking of the iron-limited areas, as macronutrient inputs from below the euphotic zone decline with climate change under both RCP scenarios (cf. Figs. $6,14)$. The major HNLC regions all decrease in spatial extent, with the biggest decrease in the eastern equatorial Pacific. The subarctic North Pacific HNLC areal extent is strongly underestimated in the 1990s and shrinks further with climate change, leading most of the region to become $\mathrm{N}$ limited for the diatoms under RCP8.5. For the diazotrophs, the iron-limited areas also decrease, shifting to phosphorus limitation. $\mathrm{P}$ limitation also increases for the diatoms and small phytoplankton in the Sargasso Sea region (Figs. 6, 14). The areas of strong nutrient $\mathrm{N}$ limitation (darker maroon shade in Figs. 6, 14) expand for all phytoplankton groups, particularly under RCP8.5.

Climate change results in shifts in the phytoplankton community composition, with a decreasing fraction of production by diatoms under both RCP scenarios. The proportion of primary production by the small phytoplankton increases because they are more efficient at taking up nutrients at low concentrations (Fig. 15, Table 1). The fraction of global primary production contributed by diatoms declines from $37 \%$ to $35 \%$ under RCP 4.5 and to $29 \%$ under RCP8.5 (Table 1). This community shift with climate change is consistent with the conceptual model put forth by Marinov et al. (2010), with decreasing nutrient concentrations impacting diatoms more strongly than the smaller phytoplankton. The largest decreases in diatom production are seen in the high-latitude North Atlantic, where the collapse of deep winter mixing greatly reduces the flux of nutrients into surface waters (Fig. 15). Large decreases in diatom productivity are also seen in the Arctic and parts of the western Pacific. In both regions, surface nutrient concentrations have been reduced relative to the 1990s. These community shifts significantly impact particle 
A) Diatom Growth Limitation RCP 4.5 2090s

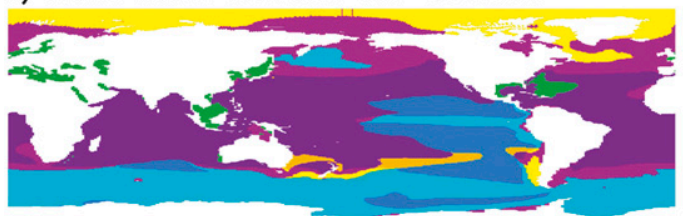

Nitrogen $58.87 \%$, Iron $34.84 \%$, Silico $2.705 \%$, Phosphorus $3.578 \%$ Replete $0.000 \%$

"Nitrogen IIron "Phosphorus ISilicon -Temperature Replete

B) Small Phytoplankton Growth Limitation

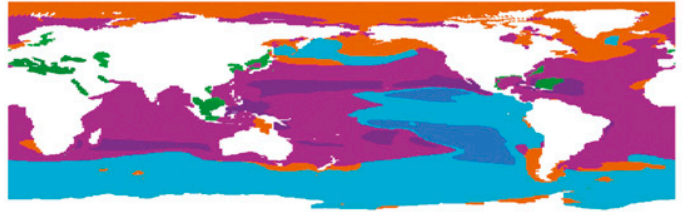

Nitrogen 53.67\%, Iron $36.06 \%$, Phosphorus $1.036 \%$ Replete $9.228 \%$

C) Diazotroph Growth Limitation

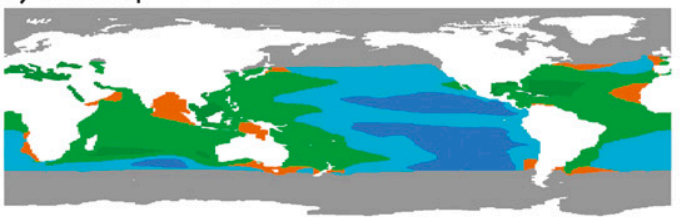

Nitrogen $0.000 \%$, Iron $33.70 \%$, Phosphorus $33.17 \%$ Replete $4.164 \%$, Temperoture $28.95 \%$
A) Diatom Growth Limitotion RCP $8.52090 \mathrm{~s}$

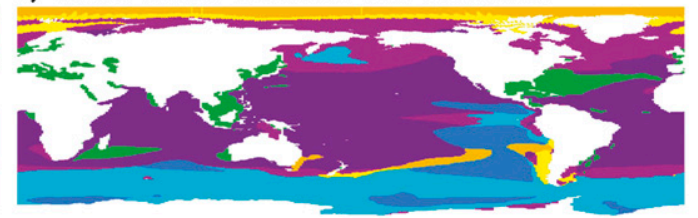

Nitrogen $\mathbf{6 2 . 6 1 \%}$, Iron $\mathbf{2 6 . 8 9 \%}$, Silico $\mathbf{2 . 5 8 2 \%}$, Phosphorus $\mathbf{7 . 8 9 8 \%}$ Replete $0.000 \%$

nitrogen IIron aPhosphorus II Silicon

Temperoture Replete

B) Small Phytoplankton Growth Limitation

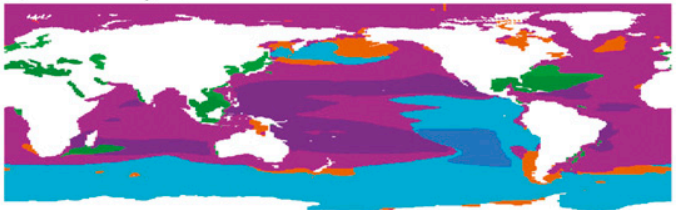

Nitrogen $62.90 \%$, Iron $30.57 \%$, Phosphorus $2.111 \%$

Replete $4.408 \%$

C) Diazotroph Growth Limitation

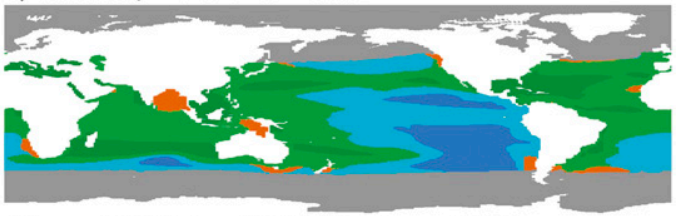

Nitrogen $0.000 \%$, Iron $28.26 \%$, Phosphorus $43.67 \%$

Replete $2.537 \%$, Temperoture $25.52 \%$

FIG. 14. The factors most limiting growth over the annual time scale for the 2090s under the RCP4.5 and RCP8.5 scenarios are displayed. Darker shade of each color indicates stronger nutrient limitation (growth reduced by $>50 \%$ from maximum). A group is nutrient replete if annual mean nutrient concentrations are sufficient for growth at $>90 \%$ of their maximal rates.

export ratios and the export flux, as diatoms export much more efficiently than the other phytoplankton groups (Moore et al. 2002b, 2004). The relative diatom production increases modestly in some of the HNLC areas because of increased iron inputs from below and because of increasing $\mathrm{N}$ limitation and reduced production in adjacent "upstream" regions, allowing for increased lateral inputs of dissolved iron to the HNLC regions. Shifts in the westerly winds intensity and location also play a role in the Southern Ocean. Over much of the low-latitude regions, increasing stratification and increasing nutrient stress reduces the diatom contribution to total production by $3 \%-10 \%$ in the RCP8.5 simulation (Fig. 15).

We examine the shifts in net primary production and sinking export production in Figs. 16 and 17. The spatial patterns of change under the RCP4.5 and 8.5 scenarios are remarkably similar in these two figures, with a larger magnitude of change under RCP8.5. Primary and export production declines sharply in the high-latitude North Atlantic and throughout most of the tropics and subtropics, except for the eastern equatorial Pacific (decrease $>30 \%$ in many areas). The largest declines in production occur in the high-latitude North Atlantic because of the reductions in deep winter mixing. There are also sharp declines in the western equatorial Pacific driven by increasing stratification and the shrinking equatorial HNLC region, with reduced vertical nutrient flux and reduced lateral input of nutrients from the east. Changes in nutrient inputs and ecosystem structure driven by climate change lead to a weakening of downward fluxes of organic carbon at $100-\mathrm{m}$ depth by more than $1 \mathrm{PgC} \mathrm{yr}^{-1}$ (13\% decrease) under RCP8.5 (Table 1, Fig. 17).

In the Arctic Ocean net primary production (NPP) and export production increase in some shelf regions, even as overall Arctic nutrient and chlorophyll concentrations decline (Figs. 11, 13, 16, 17). The reduced ice cover, longer growing season, and warmer temperatures (Vavrus et al. 2012) allow for more production and export in some shelf regions, even as mean chlorophyll concentrations decline. In the central Arctic, there are declines in export production and a small increase in NPP (Figs. 16, 17). This is possible because there is a community shift from very strong diatom dominance in the 1990s to a mixed community in the 2090s (Fig. 15). The increased fraction of production by small phytoplankton decreases the export ratio, allowing NPP to increase even as export decreases. 


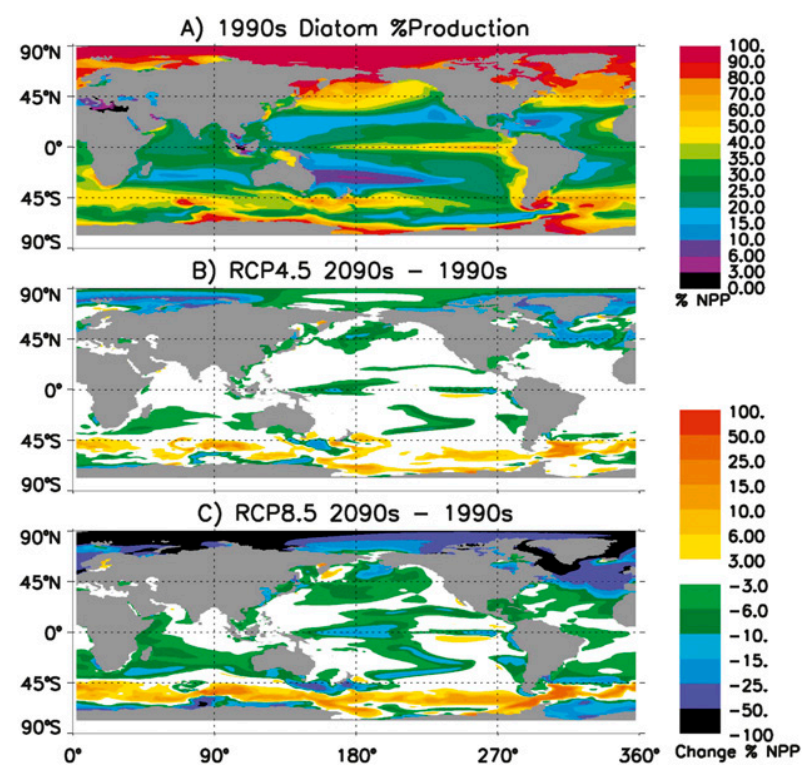

FIG. 15. The percentage of total NPP by the diatom functional group for the 1990s is compared with the 2090s under the RCP4.5 and RCP8.5 scenarios.

There are modest increases in primary and export production in the HNLC areas, mainly because of the reductions in iron utilization and scavenging losses in adjacent "upstream" regions. The strongest effect is in the eastern equatorial Pacific, where decreased western Pacific production and export contributes to enhanced lateral transport of iron to the eastern equatorial Pacific in the Equatorial Undercurrent (Figs. 13, 16, 17). Changes in ocean circulation also drive increased advective iron input to the eastern equatorial Pacific and to the Southern Ocean (Misumi et al. 2013). Similarly, in the Southern Hemisphere there is reduced export and NPP in the subtropical $\mathrm{N}$-limited areas, allowing for higher iron concentrations along the boundary between $\mathrm{N}$-limited and Fe-limited waters and increased advection of iron into the Southern Ocean HNLC region, fueling modestly increased NPP and export production (cf. Figs. 12-17). This pattern is strongest in the Atlantic sector, but can be seen to some extent in each basin. In the North Pacific, the increased iron concentrations in the western subtropical Pacific lead to increased advection of iron into the subarctic North Pacific HNLC region, driving increased diatom production, NPP, and export production, particularly on the western side of the basin under RCP8.5 (cf. Figs. 12-17). This is the region where the diatoms are still iron limited (Fig. 14).

We examine the end-of-century relative change in key biogeochemical fluxes as a function of the global mean sea surface temperature change in Fig. 18. The declines in POC export, NPP, and N fixation were very linear with the mean temperature increase $\left(r^{2}>0.99\right.$ for linear

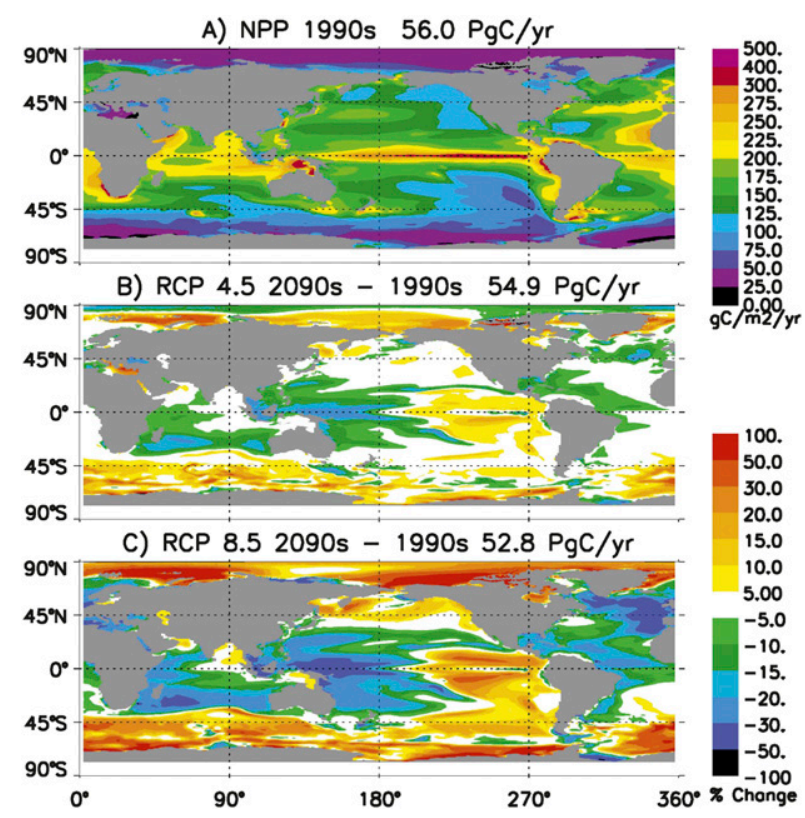

FIG. 16. Annual mean NPP for the 1990s is compared with the 2090s under the RCP4.5 and RCP8.5 scenarios.

regression for these variables). This is somewhat surprising given the rather complex spatial patterns of change (seen in the preceding figures) that go into these globally integrated fluxes. These spatial patterns do have similar spatial structure under RCP4.5 and RCP8.5. The decrease in the percent of total production by the diatoms was less linear $\left(r^{2}=0.95\right)$. The small decrease in the export of sinking $\mathrm{CaCO}_{3}$ was nonlinear, with higher export under RCP8.5 than RCP4.5. As calcification is a dynamic fraction of primary production by the small phytoplankton group in the CESM, the higher $\mathrm{CaCO}_{3}$ export under RCP8.5 is likely due to the stronger shift in community composition from diatoms to the small phytoplankton. We note that ocean acidification and carbon chemistry do not currently impact calcification rates or $\mathrm{CaCO}_{3}$ dissolution in the CESM1(BGC). Recent model studies that include these processes suggest that both will likely be modified by the ongoing ocean acidification-driven changes in carbon chemistry (e.g., Gansto et al. 2011; Pinsonneault et al. 2012; Ilyina and Zeebe 2012).

\section{Discussion}

The CESM1(BGC) reproduces the observed surface nutrient distributions and phytoplankton biomass at the global scale. It also captures the global-scale patterns in surface DIC and $p \mathrm{CO}_{2}$ values (Long et al. 2013). Therefore, it is suitable for studying the biological feedbacks with climate change in coupled carbon-climate simulations. 
A) Sinking POC 1990s 8.06 PgC
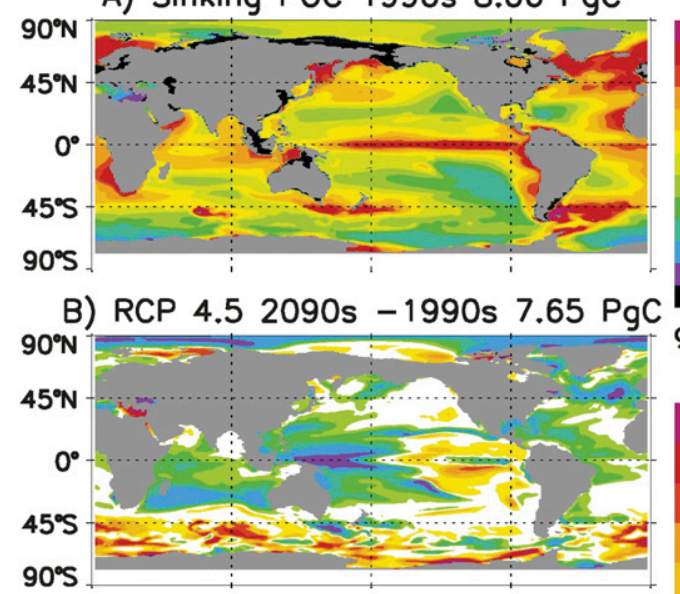

C) RCP $8.52090 \mathrm{~s}-1990 \mathrm{~s} 6.99 \mathrm{PgC}$

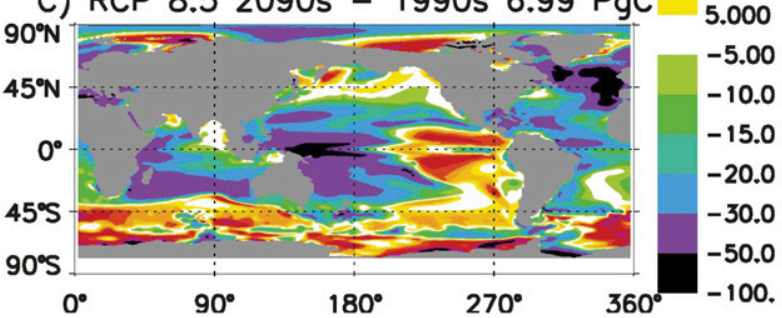

FIG. 17. The annual mean sinking particulate organic carbon flux at 100-m depth for the 1990s is compared with the 2090s under the RCP4.5 and RCP8.5 scenarios.

Significant biases remain in the simulated subsurface oxygen, which leads to deficiencies in the simulation of water column denitrification.

The CESM1(BGC) prediction of decreased sinking export production due to climate change by $13 \%$ is similar to results from a number of previous studies, but higher than seen in CCSM3.1, where export production declined by only $2 \%$ versus the preindustrial era under the SRES A2 scenario (Steinacher et al. 2010). Other models have found declines in export production of $\sim 5 \%-10 \%$ over the twenty-first century (e.g., Bopp et al. 2001; Fung et al. 2005; Schmittner et al. 2008; Steinacher et al. 2010; Taucher and Oschlies 2011).

Decreases in net primary production have been seen in some of these studies (Steinacher et al. 2010), but some models show increased NPP, even while export production is decreasing (Schmittner et al. 2008; Taucher and Oschlies 2011). This can happen if there is increased recycled production (lower export ratios). Increasing NPP has been attributed to a strong temperature sensitivity of plankton metabolic and growth rates (Taucher and Oschlies 2011). Phytoplankton community composition is a key factor affecting export efficiency; in CESM1(BGC), this manifests as a difference between diatoms and nondiatoms. The CESM1(BGC) simulates

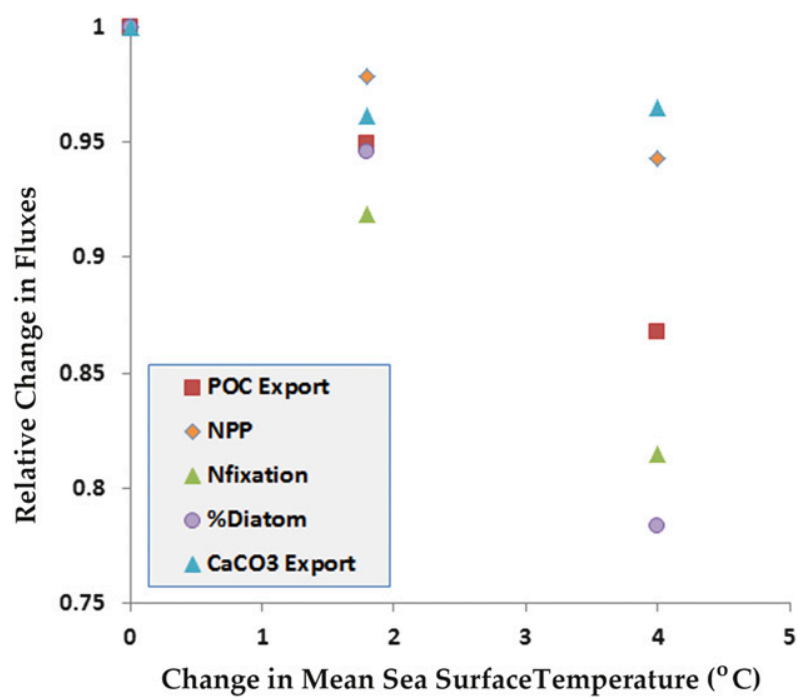

FIG. 18. The relative change in key ecosystem fluxes are plotted as a function of the increase in global mean SST under RCP4.5 $\left(+1.8^{\circ} \mathrm{C}\right)$ and under RCP8.5 $\left(+4^{\circ} \mathrm{C}\right)$.

globally declining NPP, even with a Q10 factor of 2.0, leading to a positive influence of warming on phytoplankton growth rates. Most models assume more efficient export by diatoms than smaller phytoplankton, but the degree to which the export efficiency differs varies considerably and is inherently uncertain. The export efficiency of the diatoms in the CESM1(BGC) is lower than seen in some other models, typically $<45 \%$ depending on the balance between loss processes (grazing, nongrazing mortality, and aggregation). In some models, the export efficiency of diatoms can be much higher. The analysis of Dunne et al. (2005) suggested high export efficiency for the large phytoplankton. The correct value for this export efficiency is not strongly constrained by available observations. Models with very low export efficiency for small phytoplankton and very high efficiency for diatoms are more likely to show increased NPP even as surface nutrient concentrations decline because of community-driven shifts in the export ratio. This pattern was seen in our results in the Arctic region but was not a strong enough effect to increase NPP in lower-latitude regions, where the shifts in community composition were more modest (Figs. 15-17). The percentage of primary production by diatoms declined from $37 \%$ in the 1990 s to $29 \%$ at the end of the century under the RCP8.5 scenario. This community shift reduces export efficiency and the export ratio in the model, but the decreases in production due to reduced nutrient inputs had a stronger effect. Thus, production declines over most of the low latitudes in the CESM. Other models with a larger difference in export efficiency between diatoms and small phytoplankton might 
show increased primary production even as export production declined.

This study showed modest increases in NPP and export production in the major HNLC regions. Some other recent studies have found similar results. All four models examined by Steinacher et al. (2010) had modestly increased production in the subarctic North Pacific and in the Southern Ocean. Only CCSM3 had increases in the equatorial Pacific, with large decreases in equatorial Pacific export seen in one model (Steinacher et al. 2010). The increased HNLC export partially compensates for the declines in export seen over most of the non-HNLC ocean. Without the increased export production in the HNLC regions (where annual mean surface nitrate is $>1.0 \mu \mathrm{M}$ in the 2090s and latitude is $<65^{\circ} \mathrm{N}$; see Figs. 11, 17), global export production would have declined by $1.34 \mathrm{PgC} \mathrm{yr}^{-1}$ by the end of the century under the RCP8.5. Thus, the increased export production in the HNLC regions partially compensated for the declines in export elsewhere (an offset of $25 \%$ ). A similar offset was seen under RCP4.5 (decline in export offset by $21 \%$ due to HNLC areas). There are similar upstream/downstream (seesaw type) compensating effects when the atmospheric Fe deposition to the HNLC regions changes significantly (e.g., Moore et al. 2006; Krishnamurthy et al. 2009).

Considerable uncertainty remains in our understanding of the marine iron cycle, and current models differ considerably in the inputs of iron to the oceans (from both the atmosphere and the sediments) and in the treatment of ligand dynamics and scavenging losses for iron. However, all have been tuned to try and match the limited observations of dissolved iron concentrations. Our results regarding the "downstream" compensating influence on export production would seem to be robust across models that reasonably capture the observed iron distributions. As increasing stratification increase macronutrient limitation, there will be an increased lateral flux of iron to adjacent HNLC areas. Models without explicit, dynamic iron cycling (including those with a static, prescribed iron limitation) would not capture these compensating effects.

Decreasing particulate matter export as ocean biology responds to climate change represents a positive feedback on climate warming by weakening the ocean sink for atmospheric $\mathrm{CO}_{2}$. Anthropogenic $\mathrm{CO}_{2}$ uptake by the oceans is lowering $\mathrm{pH}$ and altering carbonate chemistry in nonlinear ways that also weaken the ability of oceans to take up additional $\mathrm{CO}_{2}$. Ocean uptake of atmospheric $\mathrm{CO}_{2}$ peaks midcentury, under the RCP4.5 scenario, and declines modestly by the end of the century as atmospheric concentrations stabilize, with uptake during the 2090s slightly below 1990s values because of changes in surface water carbon chemistry (Table 1; Long et al. 2013, manuscript submitted to J. Climate). Under the RCP8.5 scenario, annual uptake levels out at about $5 \mathrm{PgC} \mathrm{yr}^{-1}$ in the 2070s (at atmospheric $\mathrm{CO}_{2}$ levels of $\sim 600 \mathrm{ppm}$ ) because of the carbonate chemistry feedbacks (Long et al. 2013, manuscript submitted to J. Climate). This suggests that the ongoing climate warming will increase even more rapidly in the twentysecond century and beyond if fossil fuel emissions continue to rise.

A caveat when considering the results from this study, the other CMIP5 models, and previous studies is that a number of processes that may significantly alter marine ecosystem structure and upper-ocean biogeochemistry are not yet fully incorporated into Earth system models (ESMs). Ocean acidification driven by the anthropogenic $\mathrm{CO}_{2}$ emissions has recently received a lot of attention (e.g., Doney et al. 2009c; Blackford 2010). However, the community is still working on quantifying how this process may affect the growth and survival of calcifying organisms and how it may increase growth rates of other organisms, such as diazotrophs (e.g., Hutchins et al. 2007). Most ESMs, including the CESM, do not yet include the physiological response of organisms to acidification. Increasing atmospheric deposition of $\mathrm{N}$ and $\mathrm{S}$ will contribute to ocean acidification, particularly near the continents (Doney et al. 2007). Increasing anthropogenic nutrient loading through riverine inputs is also often not included in ESMs. These riverine nutrient inputs may increase coastal and shelf water production and hypoxia.

Many of the coarse-resolution ESM ocean models have problems similar to the CESM in simulating ocean oxygen distributions and the OMZs. This is problematic since it has been suggested that OMZs have been expanding in recent decades (Stramma et al. 2008) and will continue to expand over the coming century (Keeling et al. 2010). This process will act to increase marine water column denitrification, as well as marine nitrous oxide production, with implications for marine primary production and the radiative properties of the atmosphere (positive feedback). The current-generation ESMs are poorly suited to studying these links between the $\mathrm{C}, \mathrm{O}$, and $\mathrm{N}$ cycles, with circulation/ventilation deficiencies and simple parameterizations of biological processes in the OMZs. Most models do not yet include mechanistic representations of oceanic production of nitrous oxide, methane, or dimethyl sulfide, which are all trace gases that can impact climate. Finally, variability in the atmospheric deposition of iron (and its solubility) to the oceans, from mineral dust and combustion sources (Mahowald and Luo 2003; Luo et al. 2008; Fan et al. 2006; Sholkovitz et al. 2012), could significantly impact 
phytoplankton community dynamics in the HNLC areas and nitrogen fixation in the more oligotrophic regions (e.g., Moore et al. 2006; Krishnamurthy et al. 2009).

Comparing our results under the RCP4.5 and RCP8.5 scenarios, it is apparent that the RCP4.5 scenario that leads to a stable climate and atmospheric $\mathrm{CO}_{2}$ concentrations by the end of the century will act to minimize the perturbations to key biogeochemical fluxes and upper-ocean nutrient concentrations. In contrast, under the RCP8.5 high-fossil-fuel-burning scenario, at the end of the century atmospheric $\mathrm{CO}_{2}$ concentrations are still increasing exponentially and global mean SST is still rising rapidly (Long et al. 2013, manuscript submitted to $J$. Climate). Given the linear nature of the response to increased temperature of key ocean biogeochemical fluxes (Fig. 18), this suggests that ocean biogeochemistry would be increasingly perturbed, with even larger reductions in primary and export production over the following centuries, eventually threatening marine ecosystem health at the global scale.

Acknowledgments. We thank the editor and three anonymous reviewers for helpful comments and suggestions. The CESM project is supported by the National Science Foundation and the Office of Science (BER) of the U.S. Department of Energy. Computing resources were provided by the Climate Simulation Laboratory at NCAR's Computational and Information Systems Laboratory (CISL), sponsored by the National Science Foundation and other agencies. This research was enabled by CISL compute and storage resources. Bluefire, a 4064-processor IBM Power6 resource with a peak of 77 TeraFLOPS, provided more than 7.5 million computing hours; the GLADE high-speed disk resources provided 0.4 PB of dedicated disk; and CISL's 12-PB HPSS archive provided over $1 \mathrm{~PB}$ of storage in support of this research project. S.C.D. acknowledges support of Collaborative Research: Improved Regional and Decadal Predictions of the Carbon Cycle (NSF AGS-1048827). This work was supported by NSF grants (ARC-0902045 and AGS-1021776 to Moore and AGS1048890 to Moore, Lindsay, and Doney).

\section{REFERENCES}

Antonov, J. I., and Coauthors, 2010: Salinity. Vol. 2, World Ocean Atlas 2009, NOAA Atlas NESDIS 69, 184 pp.

Armstrong, R. A., C. Lee, J. I. Hedges, S. Honjo, and G. W. Stuart, 2002: A new, mechanistic model for organic carbon fluxes in the ocean based on the quantitative association of POC with ballast minerals. Deep-Sea Res. II, 49, 219-236.

Bates, S. C., B. Fox-Kemper, S. R. Jayne, W. G. Large, S. Stevenson, and S. G. Yeager, 2012: Mean biases, variability, and trends in air-sea fluxes and sea surface temperature in the CCSM4. J. Climate, 25, 7781-7801.

Bianchi, D., J. P. Dunne, J. L. Sarmiento, and E. D. Galbraith, 2012: Data-based estimates of suboxia, denitrification, and $\mathrm{N}_{2} \mathrm{O}$ production in the ocean and their sensitivities to dissolved $\mathrm{O}_{2}$. Global Biogeochem. Cycles, 26, GB2009, doi:10.1029/ 2011GB004209.

Blackford, J. C., 2010: Predicting the impacts of ocean acidification: Challenges from an ecosystem perspective. J. Mar. Syst., 81, 12-18.

Bopp, L., P. Monfray, O. Aumont, J. L. Dufresne, H. Le Treut, G. Madec, L. Terray, and J. C. Orr, 2001: Potential impact of climate change on marine export production. Global Biogeochem. Cycles, 15, 81-99, doi:10.1029/1999GB001256.

Boyd, P. W., and S. C. Doney, 2002: Modelling regional responses by marine pelagic ecosystems to global climate change. Geophys. Res. Lett., 29, 1806, doi:10.1029/2001GL014130.

Capotondi, A., M. A. Alexander, N. A. Bond, E. N. Curchitser, and J. D. Scott, 2012: Enhanced upper ocean stratification with climate change in the CMIP3 models. J. Geophys. Res., 117, C04031, doi:10.1029/2011JC007409.

Codispoti, L. A., J. A. Brandes, J. P. Christensen, A. H. Devol, S. W. A. Naqvi, H. W. Paerl, and T. Yoshinari, 2001: The oceanic fixed nitrogen and nitrous oxide budgets: Moving targets as we enter the anthropocene? Sci. Mar., 65 (Suppl.), 85-105.

Comiso, J., 1999: Bootstrap sea ice concentrations from NIMBUS7 SMMR and DMSP SSM/I, 1979-2007. National Snow and Ice Data Center, Boulder, CO, digital media. [Available online at www.nsidc.org.]

Danabasoglu, G., S. C. Bates, B. P. Briegleb, S. R. Jayne, M. Jochum, W. G. Large, S. Peacock, and S. G. Yeager, 2011: The CCSM4 ocean component. J. Climate, 25, 1361-1389.

DeVries, T., C. Deutsch, F. Primeau, B. Chang, and A. Devol, 2012: Global rates of water-column denitrification derived from nitrogen gas measurements. Nat. Geosci., 5, 547-550, doi:10.1038/ ngeo1515.

- — - P. A. Rafter, and F. Primeau, 2013: Marine denitrification rates determined from a global 3-D inverse model. Biogeosciences, 10, 2481-2496, doi:10.5194/bg-10-2481-2013.

Dietze, H., and U. Loeptien, 2013: Revisiting "nutrient trapping" in global coupled biogeochemical circulation models. Global Biogeochem. Cycles, 27, 265-284, doi:10.1002/ gbc. 20029 .

Doney, S. C., and H. W. Ducklow, 2006: A decade of synthesis and modeling in the US Joint Global Ocean Flux Study. Deep-Sea Res. II, 53, 451-458, doi:10.1016/j.dsr2.2006.01.019.

N. Mahowald, I. Lima, R. A. Feely, F. T. Mackenzie, J.-F. Lamarque, and P. J. Rasch, 2007: Impact of anthropogenic atmospheric nitrogen and sulfur deposition on ocean acidification and the inorganic carbon system. Proc. Natl. Acad. Sci. USA, 104, 14580-14585, doi:10.1073/ pnas.0702218104.

_ I. Lima, R. A. Feely, D. M. Glover, K. Lindsay, N. Mahowald, J. K. Moore, and R. Wanninkhof, 2009a: Mechanisms governing interannual variability in upper-ocean inorganic carbon system and air-sea $\mathrm{CO}_{2}$ fluxes: Physical climate and atmospheric dust. Deep-Sea Res. II, 56, 640-655, doi:10.1016/ j.dsr2.2008.12.006.

, and Coauthors, 2009b: Skill metrics for confronting global upper ocean ecosystem-biogeochemistry models against field and remote sensing data. J. Mar. Syst., 76, 95-112, doi:10.1016/ j.jmarsys.2008.05.015. 
— V. J. Fabry, R. A. Feely, and J. A. Kleypas, 2009c: Ocean acidification: The other $\mathrm{CO}_{2}$ problem. Annu. Rev. Mar. Sci., 1, 169-192.

- , and Coauthors, 2012: Climate change impacts on marine ecosystems. Annu. Rev. Mar. Sci., 4, 11-37, doi:10.1146/ annurev-marine-041911-111611.

Dunne, J. P., R. A. Armstrong, A. Gnanadesikan, and J. L. Sarmiento, 2005: Empirical and mechanistic models for the particle export ratio. Global Biogeochem. Cycles, 19, GB4026, doi:10.1029/ 2004GB002390.

Fan, S.-M., W. J. Moxim, and H. Levy II, 2006: Aeolian input of bioavailable iron to the ocean. Geophys. Res. Lett., 33, L07602, doi:10.1029/2005GL024852.

Friedrichs, M. A. M., and Coauthors, 2007: Assessment of skill and portability in regional marine biogeochemical models: Role of multiple planktonic groups. J. Geophys. Res., 112, C08001, doi:10.1029/2006JC003852.

Frölicher, T. L., F. Joos, G.-K. Plattner, M. Steinacher, and S. C. Doney, 2009: Natural variability and anthropogenic trends in oceanic oxygen in a coupled carbon cycle-climate model ensemble. Global Biogeochem. Cycles, 23, GB1003, doi:10.1029/2008GB003316.

Fung, I. Y., S. C. Doney, K. Lindsay, and J. John, 2005: Evolution of carbon sinks in a changing climate. Proc. Natl. Acad. Sci. USA, 102, 11 201-11206, doi:10.1073/pnas.0504949102.

Gansto, R., F. Joos, and M. Gehlen, 2011: Sensitivity of pelagic calcification to ocean acidification. Biogeosciences, 8, 433-458, doi:10.5194/bg-8-433-2011.

Garcia, H. E., R. A. Locarnini, T. P. Boyer, J. I. Antonov, O. K. Baranova, M. M. Zweng, and D. R. Johnson, 2010a: Dissolved Oxygen, Apparent Oxygen Utilization, and Oxygen Saturation. Vol. 3, World Ocean Atlas 2009, NOAA Atlas NESDIS 70, 344 pp.

,,$---\longrightarrow$, M. M. Zweng, O. K. Baranova, and D. R. Johnson, 2010b. Nutrients (Phosphate, Nitrate, Silicate). Vol. 4, World Ocean Atlas 2009, NOAA Atlas NESDIS 71, $398 \mathrm{pp}$

Gent, P. R., and Coauthors, 2011: The Community Climate System Model version 4. J. Climate, 24, 4973-4991.

Getzlaff, J., and H. Dietze, 2013: Effects of increased isopycnal diffusivity mimicking the unresolved equatorial intermediate current system in an earth system model. Geophys. Res. Lett., 40, 2166-2170, doi:10.1002/grl.50419.

Gnanadesikan, A., J. P. Dunne, and J. John, 2012: Understanding why the volume of suboxic waters does not increase over centuries of global warming in an Earth System Model. Biogeosciences, 9, 1159-1172.

Gruber, N., 2004: The dynamics of the marine nitrogen cycle and its influence on atmospheric $\mathrm{CO}_{2}$ variations. The Ocean Carbon Cycle, M. Follows and T. Oguz, Eds., Kluwer Academic, 97-148.

Han, Q., J. K. Moore, C. Zender, C. Measures, and D. Hydes, 2008: Constraining oceanic dust deposition using surface ocean dissolved Al. Global Biogeochem. Cycles, 22, GB2003, doi:10.1029/2007GB002975.

Holl, C. M., and J. P. Montoya, 2005: Interactions between nitrate uptake and nitrogen fixation in continuous cultures of the marine diazotroph Trichodesmium (cyanobacteria). J. Phycol., 41, 1178-1183.

Hood, R. R., and Coauthors, 2006: Pelagic functional group modeling: Progress, challenges, and prospects. Deep-Sea Res. II, 53, 459-512.

Hunke, E. C., and W. H. Lipscomb, 2008: CICE: The Los Alamos sea ice model user's manual, version 4. Tech. Rep.
LA-CC-06-012, Los Alamos National Laboratory, Los Alamos, NM, 76 pp.

Hurrell, J. W., and Coauthors, 2013: The Community Earth System Model: A Framework for Collaborative Research. Bull. Amer. Meteor. Soc., in press.

Hutchins, D. A., F.-X. Fu, Y. Zhang, M. E. Warner, Y. Feng, K. Portune, P. W. Bernhardt, and M. R. Mulholland, 2007: $\mathrm{CO}_{2}$ control of Trichodesmium $\mathrm{N}_{2}$ fixation, photosynthesis, growth rates, and elemental ratios: Implications for past, present, and future ocean biogeochemistry. Limnol. Oceanogr., 52, 1293-1304.

Ilyina, T., and R. E. Zeebe, 2012: Detection and projection of carbonate dissolution in the water column and deep-sea sediments due to ocean acidification. Geophys. Res. Lett., 39, L06606, doi:10.1029/2012GL051272.

Jahn, A., and Coauthors, 2012: Late-twentieth-century simulation of Arctic sea ice and ocean properties in the CCSM4. J. Climate, 25, 1431-1452.

Jin, X., N. Gruber, J. P. Dunne, J. L. Sarmiento, and R. A. Armstrong, 2006: Diagnosing the contribution of phytoplankton functional groups to the production and export of particulate organic carbon, $\mathrm{CaCO}_{3}$, and opal from global nutrient and alkalinity distributions. Global Biogeochem. Cycles, 20, GB2015, doi:10.1029/ 2005GB002532.

Joos, F., G. K. Plattner, T. F. Stocker, O. Marchal, and A. Schmittner, 1999: Global warming and marine carbon cycle feedbacks and future atmospheric $\mathrm{CO}_{2}$. Science, 284, 464-467.

Karl, D., and Coauthors, 2002: DiN fixation in the world's oceans. Biogeochemistry, 57/58, 47-98.

Keeling, R. F., A. Körtzinger, and N. Gruber, 2010: Oxygen deoxygenation in a warming world. Annu. Rev. Mar. Sci., 2, 199-229.

Keppel-Aleks, G., and Coauthors, 2013: Atmospheric carbon dioxide variability in the Community Earth System Model: Evaluation and transient dynamic during the twentieth and twenty-first centuries. J. Climate, 26, 4447-4475.

Key, R. M., and Coauthors, 2004: A global ocean carbon climatology: Results from Global Data Analysis Project (GLODAP). Global Biogeochem. Cycles, 18, GB4031, doi:10.1029/ 2004 GB002247.

Kriest, I., and A. Oschlies, 2008: On the treatment of particulate organic matter sinking in large-scale models of marine biogeochemical cycles. Biogeosciences, 5, 55-72.

Krishnamurthy, A., J. K. Moore, C. S. Zender, and C. Luo, 2007: Effects of Atmospheric inorganic nitrogen deposition on ocean biogeochemistry. J. Geophys. Res., 112, G02019, doi:10.1029/ 2006JG000334.

,-- N. Mahowald, C. Luo, S. C. Doney, K. Lindsay, and C. S. Zender, 2009: Impacts of increasing anthropogenic soluble iron and nitrogen deposition on ocean biogeochemistry. Global Biogeochem. Cycles, 23, GB3016, doi:10.1029/2008GB003440.

,,,,---- and C. S. Zender, 2010: Impacts of atmospheric nutrient inputs on marine biogeochemistry. J. Geophys. Res., 115, G01006, doi:10.1029/2009JG001115.

Kwon, E. Y., and F. Primeau, 2006: Optimization and sensitivity study of a biogeochemistry ocean model using an implicit solver and in situ phosphate data. Global Biogeochem. Cycles, 20, GB4009, doi:10.1029/2005GB002631.

Lamarque, J.-F., and Coauthors, 2010: Historical (1850-2000) gridded anthropogenic and biomass burning emissions of reactive gases and aerosols: methodology and application. Atmos. Chem. Phys., 10, 7017-7039, doi:10.5194/ acp-10-7017-2010. 
Lee, K., 2001: Global net community production estimated from the annual cycle of surface water total dissolved inorganic carbon. Limnol. Oceanogr., 46, 1287-1297.

Le Quéré, C., and Coauthors, 2005: Ecosystem dynamics based on plankton functional types for global ocean biogeochemistry models. Global Change Biol., 11, 2016-2040, doi:10.1111/ j.1365-2486.2005.1004.x.

Locarnini, R. A., A. V. Mishonov, J. I. Antonov, T. P. Boyer, H. E. Garcia, O. K. Baranova, M. M. Zweng, and D. R. Johnson, 2010: Temperature. Vol. 1, World Ocean Atlas 2009, NOAA Atlas NESDIS 68, 184 pp.

Long, M., K. Lindsay, S. Peacock, J. K. Moore, and S. C. Doney, 2013: Twentieth-century oceanic carbon uptake and storage in CESM1(BGC). J. Climate, 26, 6775-6800, doi:10.1175/ JCLI-D-12-00184.1.

Lovenduski, N. S., N. Gruber, and S. C. Doney, 2008: Toward a mechanistic understanding of the decadal trends in the Southern Ocean carbon sink. Global Biogeochem. Cycles, 22, GB3016, doi:10.1029/2007GB003139.

Luo, C., N. M. Mahowald, and J. del Corral, 2003: Sensitivity study of meteorological parameters on mineral aerosol mobilization, transport, and distribution. J. Geophys. Res., 108, 4447, doi:10.1029/2003JD003483.

,-- , T. Bond, P. Y. Chuang, P. Artaxo, R. Siefert, Y. Chen, and J. Schauer, 2008: Combustion iron distribution and deposition. Global Biogeochem. Cycles, 22, GB1012, doi:10.1029/ 2007GB002964.

Mahowald, N. M., and C. Luo, 2003: A less dusty future? Geophys. Res. Lett., 30, 1903, doi:10.1029/2003GL017880.

—_, and Coauthors, 2010: Observed 20th century desert dust variability: Impact on climate and biogeochemistry. Atmos. Chem. Phys., 10, 10875-10 893, doi:10.5194/acp-10-10875-2010.

—_, K. Lindsay, D. Rothenberg, S. C. Doney, J. K. Moore, P. Thornton, J. T. Randerson, and C. D. Jones, 2011: Desert dust and anthropogenic aerosol interactions in the Community Climate System Model coupled-carbonclimate model. Biogeosciences, 8, 387-414, doi:10.5194/ bg-8-387-2011.

Maier-Reimer, E., U. Mikolajewicz, and A. Winguth, 1996: Future ocean uptake of $\mathrm{CO}_{2}$ : Interaction between ocean circulation and biology. Climate Dyn., 12, 63-90.

Marinov, I., S. C. Doney, and I. D. Lima, 2010: Response of ocean phytoplankton community structure to climate change over the 21st century: Partitioning the effects of nutrients, temperature and light. Biogeosciences, 7, 3941-3959, doi:10.5194/ bg-7-3941-2010.

Matear, R. J., and A. C. Hirst, 1999: Climate change feedback on the future oceanic $\mathrm{CO}_{2}$ uptake. Tellus, 51B, 722-733.

Misumi, K., K. Lindsay, F. O. Bryan, J. K. Moore, S. C. Doney, D. Tsumune, and Y. Yoshida, 2013: The iron budget in ocean surface waters in the 20th and 21st centuries: Projections by the Community Earth System Model version 1. Biogeosci. Discuss., 10, 8505-8559, doi:10.5194/bgd-10-8505-2013.

Moore, J. K., and S. C. Doney, 2007: Iron availability limits the ocean nitrogen inventory stabilizing feedbacks between marine denitrification and nitrogen fixation. Global Biogeochem. Cycles, 21, GB2001, doi:10.1029/2006GB002762.

— of dissolved iron to the world ocean. Biogeosciences, 5, 631656.

— S. C. Doney, D. M. Glover, and I. Y. Fung, 2002a: Iron cycling and nutrient limitation patterns in surface waters of the world ocean. Deep-Sea Res. II, 49, 463-508.
,-- J. C. Kleypas, D. M. Glover, and I. Y. Fung, 2002b: An intermediate complexity marine ecosystem model for the global domain. Deep-Sea Res. II, 49, 403-462.

$\longrightarrow,-$, and K. Lindsay, 2004: Upper ocean ecosystem dynamics and iron cycling in a global three-dimensional model. Global Biogeochem. Cycles, 18, GB4028, doi:10.1029/2004GB002220.

,,--- , and N. Mahowald, 2006: Nitrogen fixation amplifies the ocean biogeochemical response to decadal timescale variations in mineral dust deposition. Tellus, 58B, $560-572$

Moss, R. H., and Coauthors, 2010: The next generation of scenarios for climate change research and assessment. Nature, 463, 747756, doi:10.1038/nature 08823 .

Mulholland, M. R., and D. G. Capone, 1999: Nitrogen fixation, uptake and metabolism in natural and cultured populations of Trichodesmium spp. Mar. Ecol. Prog. Ser., 188, 33-49.

$\longrightarrow$, and - 2001: Stoichiometry of nitrogen and carbon utilization in cultured populations of Trichodesmium IMS101: Implications for growth. Limnol. Oceanogr., 46, 436-443.

—, K. Ohki, and D. G. Capone, 1999: Nitrogen utilization and metabolism relative to patterns of $\mathrm{N}_{2}$ fixation in cultures of Trichodesmium NIBB1067. J. Phycol., 35, 977-988.

_ D. A. Bronk, and D. G. Capone, 2004: Dinitrogen fixation and release of ammonium and dissolved organic nitrogen by Trichodesmium IMS 101. Aquat. Microb. Ecol., 37, 85-94.

Patra, P. K., J. K. Moore, N. Mahowald, M. Uematsu, S. C. Doney, and T. Nakazawa, 2007: Exploring the sensitivity of interannual basin-scale air-sea $\mathrm{CO}_{2}$ fluxes to variability in atmospheric dust deposition using ocean carbon cycle models and atmospheric $\mathrm{CO}_{2}$ inversions. J. Geophys. Res., 112, G02012, doi:10.1029/2006JG000236.

Paulmier, A., and D. Ruiz-Pino, 2009: Oxygen minimum zones (OMZs) in the modern ocean. Prog. Oceanogr., 80, 113-128.

Pinsonneault, A. J., H. D. Matthews, E. D. Galbraith, and A. Schmittner, 2012: Calcium carbonate production response to future ocean warming and acidification. Biogeosciences, 9, 2351-2364, doi:10.5194/bg-9-2351-2012.

Riahi, K., and Coauthors, 2011: RCP 8.5-A scenario of comparatively high greenhouse gas emissions. Climatic Change, 109, 33-57, doi:10.1007/s10584-011-0149-y.

Sarmiento, J. L., J. P. Dunne, A. Gnanadesikan, R. M. Key, K. Matsumoto, and R. Slater, 2002: A new estimate of the $\mathrm{CaCO}_{3}$ to organic carbon ratio. Global Biogeochem. Cycles, 16, 1107, doi:10.1029/2002GB001919.

Schmittner, A., A. Oschlies, H. D. Matthews, and E. D. Galbraith, 2008: Future changes in climate, ocean circulation, ecosystems, and biogeochemical cycling simulated for a business-asusual $\mathrm{CO}_{2}$ emission scenario until year 4000 AD. Global Biogeochem. Cycles, 22, GB1013, doi:10.1029/2007GB002953; 23, GB3005, doi:10.1029/2009GB003577.

Sholkovitz, E. R., P. N. Sedwick, T. M. Church, A. R. Baker, and C. F. Powell, 2012: Fractional solubility of aerosol iron: Synthesis of a global-scale data set. Geochim. Cosmochim. Acta, 89, 173-189.

Smith, R. D., and Coauthors, 2010: The Parallel Ocean Program (POP) reference manual, ocean component of the Community Climate System Model (CCSM). Tech. Rep. LAUR-10-01853, Los Alamos National Laboratory, Los Alamos, NM, 141 pp. [Available online at http://www.cesm.ucar.edu/models/cesm1.0/ pop2/doc/sci/POPRefManual.pdf.].

Steinacher, M., and Coauthors, 2010: Projected 21st century decrease in marine productivity: A multi-model analysis. Biogeosciences, 7, 979-1005, doi:10.5194/bg-7-979-2010. 
Stramma, L., G. C. Johnson, J. Sprintall, and V. Mohrholz, 2008: Expanding oxygen-minimum zones in the tropical oceans. Science, 230, 655-658, doi:10.1126/science.1153847.

Taucher, J., and A. Oschlies, 2011: Can we predict the direction of marine primary production change under global warming? Geophys. Res. Lett., 38, L02603, doi:10.1029/ 2010GL045934.

Taylor, K. E., 2001: Summarizing multiple aspects of model performance in a single diagram. J. Geophys. Res., 106 (D7), 7183-7192.

Thomson, A., andCoauthors, 2011: RCP 4.5: A pathway for stabilization of radiative forcing by 2100. Climatic Change, 109, 77-94, doi:10.1007/s10584-011-0151-4.

Thornton, P. E., and Coauthors, 2009: Carbon-nitrogen interactions regulate climate-carbon cycle feedbacks: Results from an atmosphere-ocean general circulation model. Biogeochemistry, 6, 2099-2120. van Vuuren, D., and Coauthors, 2011: The representative concentration pathways: An overview. Climatic Change, 109, $1-27$.

Vavrus, S. J., M. M. Holland, A. Jahn, D. A. Bailey, and B. A. Blazey, 2012: Twenty-first-century Arctic climate change in CCSM4. J. Climate, 25, 2696-2710.

Wang, S., and J. K. Moore, 2011: Variability of primary production and air-sea $\mathrm{CO}_{2}$ flux in the Southern Ocean. Global Biogeochem. Cycles, 26, GB1008, doi:10.1029/ 2010GB003981.

,,-- F. W. Primeau, and S. Khatiwala, 2012: Simulation of anthropogenic $\mathrm{CO}_{2}$ uptake in the CCSM3.1 ocean-biogeochemical model: Comparison with data-based estimates. Biogeosciences, 9, 1321-1336.

Weijer, W., and Coauthors, 2012: The Southern Ocean and its climate in CCSM4. J. Climate, 25, 2652-2675. 